\title{
1 The mammalian cholesterol synthesis enzyme squalene \\ 2 monooxygenase is proteasomally truncated to a \\ 3 constitutively active form
}

4 Hudson W. Coates ${ }^{1}$ and Andrew J. Brown ${ }^{1 *}$

$5 \quad{ }^{1}$ School of Biotechnology and Biomolecular Sciences, UNSW Sydney, Sydney NSW 2052,

6 Australia

$7 \quad *$ To whom correspondence may be addressed. Email: aj.brown@unsw.edu.au

8 ORCIDs: H.W.C. (0000-0002-6506-5249); A.J.B. (0000-0002-4475-0116)

9 Classification: Biochemistry and Chemical Biology

10 Keywords: squalene monooxygenase, cholesterol, ERAD, proteasome, protein degradation

\section{Abstract}

Squalene monooxygenase (SM) is a rate-limiting enzyme of cholesterol synthesis that is oncogenic in a range of cancer types. SM is subject to feedback regulation via cholesterol14 induced degradation, which depends on its lipid-sensing $\mathrm{N}$ terminal regulatory domain. Here, we characterize an endogenous truncated form of SM and show that it is cholesterol-resistant, and therefore constitutively active. Truncation of SM occurs during its endoplasmic reticulumassociated degradation and requires the proteasome, which partially degrades the SM N-terminus and eliminates cholesterol-sensing elements within this region. Using mutagenesis studies, we demonstrate that partial degradation of SM depends on both an intrinsically disordered region near the truncation site and the stability of the adjacent catalytic domain. Finally, truncation converts SM from an integral to a peripheral ER membrane protein. These findings uncover an additional layer of complexity in the cellular control of cholesterol synthesis and establish SM as

\section{Introduction}

Cholesterol is a vital lipid that serves many important functions in mammalian cells, including the maintenance of membrane fluidity and integrity, the assembly of cell surface

27 microdomains for signaling and adhesion, and the synthesis of steroid hormones [1].

28 Nevertheless, excess cholesterol is cytotoxic and linked with the onset of cardiovascular disease 
and cancer $[2,3]$. It is therefore essential that cells tightly control cholesterol homeostasis by balancing its uptake, synthesis and efflux [4].

The regulation of cholesterol synthesis is especially exquisite, given the energy- and oxygen-intensive nature of the pathway. A critical point at which this regulation is exerted is squalene monooxygenase (SM, also known as squalene epoxidase or SQLE; EC:1.14.14.17), an ER-localized and rate-limiting enzyme responsible for the conversion of squalene to monooxidosqualene [5]. SM is positioned within the branch of the mevalonate pathway that is committed to cholesterol synthesis, contrasting it with the upstream rate-limiting enzyme and well-studied target of the statins, HMG-CoA reductase. Therefore, SM may be an alternative target for the treatment of hypercholesterolemia [6]. Recent years have also seen increasing recognition of SM as oncogenic in a range of malignancies including breast cancer [7], prostate cancer [8] and hepatocellular carcinoma [9]. Moreover, the SM substrate squalene is implicated either as a cytotoxic intermediate [10] or as protective against cancer cell death [11], depending on the cellular context. These reports raise the interesting prospect of targeting SM therapeutically. As the direct pharmacological inhibition of SM is toxic in mammals [12], indirect inhibition by modulating its physiological regulation may be a more viable strategy.

At the transcriptional level, SM expression is controlled by sterol regulatory elementbinding proteins, the master regulators of cholesterogenic genes [13, 14]. Acute regulation occurs at the post-translational level, where SM undergoes accelerated degradation in response to increased cholesterol levels [5]. Reciprocally, SM is stabilized by the allosteric binding of squalene $[15,16]$. These responses require the N-terminal one hundred amino acids of SM (SM-N100), a regulatory domain that is both necessary and sufficient for cholesterol- and squalene-sensing $[5,15,17,18]$. The SM-N100 domain is absent from the yeast orthologue of SM, Erg1p, despite high sequence conservation within the SM catalytic domain [5]. This suggests that the lipid-sensing capabilities of SM are unique to higher eukaryotes, in which more nuanced regulation of cholesterol synthesis is required. Cholesterol and squalene affect the stability of SM by modulating its ubiquitination by the E3 ubiquitin ligase membrane-associated RING-CH-type finger 6 (MARCHF6), thereby promoting or preventing its endoplasmic reticulum-associated degradation (ERAD) [15, 19]. Beyond MARCHF6, the ERAD of SM involves additional effectors including the AAA+-type ATPase valosin containing protein (VCP), which extracts client proteins from the ER membrane, the E2 conjugating enzyme Ube2J2, deubiquitinases, and the $26 \mathrm{~S}$ proteasome [5, 20, 21]. Plasmalogen glycerophospholipids and unsaturated fatty acids also regulate the MARCHF6-mediated degradation of SM [22, 23], implying that SM responds to other classes of lipids. However, further details of the SM ERAD mechanism remain to be elucidated.

Previously, we reported that immunoblotting of SM in HEK293 cell lysates detected fulllength SM as well as a lower-molecular weight, putatively truncated form of SM [15]. In the

66 present study, we characterize this SM variant and show that it arises from partial proteasomal 67 degradation of the SM-N100 regulatory domain (referred to herein as proteasomal truncation). 
This has been described for only two other human proteins, NF- $\kappa \mathrm{B}$ and Gli3, where it results in major changes to protein function $[24,25]$. In the case of SM, proteasomal truncation depends on an intrinsically disordered region adjacent to the truncation site, as well as the stability of the C-terminal catalytic domain. Truncation yields a constitutively active form of SM that is resistant to cholesterol-accelerated degradation and has an altered ER membrane topology. Therefore, this study uncovers an additional mode by which SM activity is regulated and establishes the first known example of a proteasomally truncated eukaryotic enzyme.

\section{Results}

\section{A truncated, cholesterol-insensitive form of SM is present in a variety of cell types}

We previously reported that anti-SM immunoblotting of HEK293 cell lysates detected full-length SM ( $\sim 64 \mathrm{kDa})$ as well as a lower molecular weight protein $(\sim 55 \mathrm{kDa})$ that was derived from the squalene epoxidase (SQLE) gene and strongly stabilized by the SM inhibitor NB-598 [15]. This protein will henceforth be referrezd to as truncated SM (trunSM). Here, we observed expression and NB-598-induced stabilization of trunSM in the commonly used HEK293T and HeLaT cell lines, as well as cell lines derived from tissues that actively synthesize cholesterol: Huh7 (liver), HepG2 (liver) and Be(2)-C (brain) (Fig. 1A). A trunSM-like protein was also detected in the $\mathrm{CHO}$ subline $\mathrm{CHO}-7$, where it was stabilized by prolonged NB-598 treatment (Supplementary Fig. S1). These observations confirmed that trunSM production is generalizable to a range of human cell types and the hamster orthologue of SM.

To further characterize trunSM, we examined its stability by treating HEK293T cells with the protein synthesis inhibitor cycloheximide in the presence or absence of NB-598. The trunSM protein was remarkably long-lived: in the absence of NB-598, $80 \%$ of its starting material remained after $24 \mathrm{~h}$ of cycloheximide treatment, compared with only $\sim 15 \%$ of fulllength SM (Fig. 1B). NB-598 had no effect on the disappearance of full-length SM but markedly induced trunSM formation, with total SM levels (the sum of full-length SM and trunSM) remaining constant during the treatment. This strongly suggested that trunSM is derived from full-length SM, and that NB-598 promotes this conversion. In a similar experiment, we used cotreatment with cycloheximide and exogenous cholesterol to test if trunSM undergoes the cholesterol-accelerated degradation characteristic of full-length SM [5]. Strikingly, cholesterol had no effect on trunSM levels, whereas accelerated degradation of SM was apparent within $2 \mathrm{~h}$

98 of cholesterol treatment (Fig. 1C). Together, these data indicated that trunSM is induced by

99 NB-598 yet resistant to both basal and cholesterol-induced degradation, raising the possibility 100 that it lacks part or all of the SM-N100 domain. This was consistent with the shift in apparent 101 molecular weight between SM and trunSM, which corresponded to a difference of $\sim 50-100$ 102 amino acids. 
A
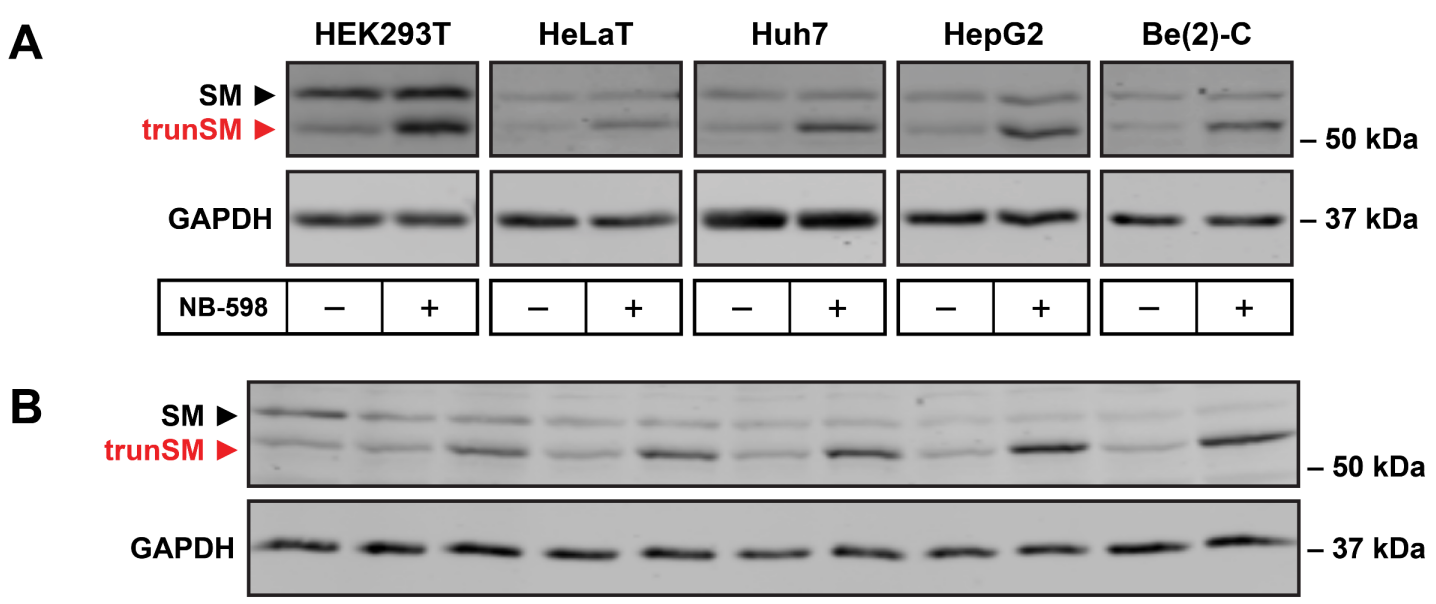

\begin{tabular}{|r|c|c|c|c|c|c|c|c|c|c|c|}
\hline NB-598 & - & - & + & - & + & - & + & - & + & - & + \\
\hline Time (h) & 0 & \multicolumn{2}{|c|}{2} & \multicolumn{2}{|c|}{4} & \multicolumn{2}{|c|}{8} & \multicolumn{2}{|c|}{16} & \multicolumn{2}{|c|}{24} \\
\hline
\end{tabular}
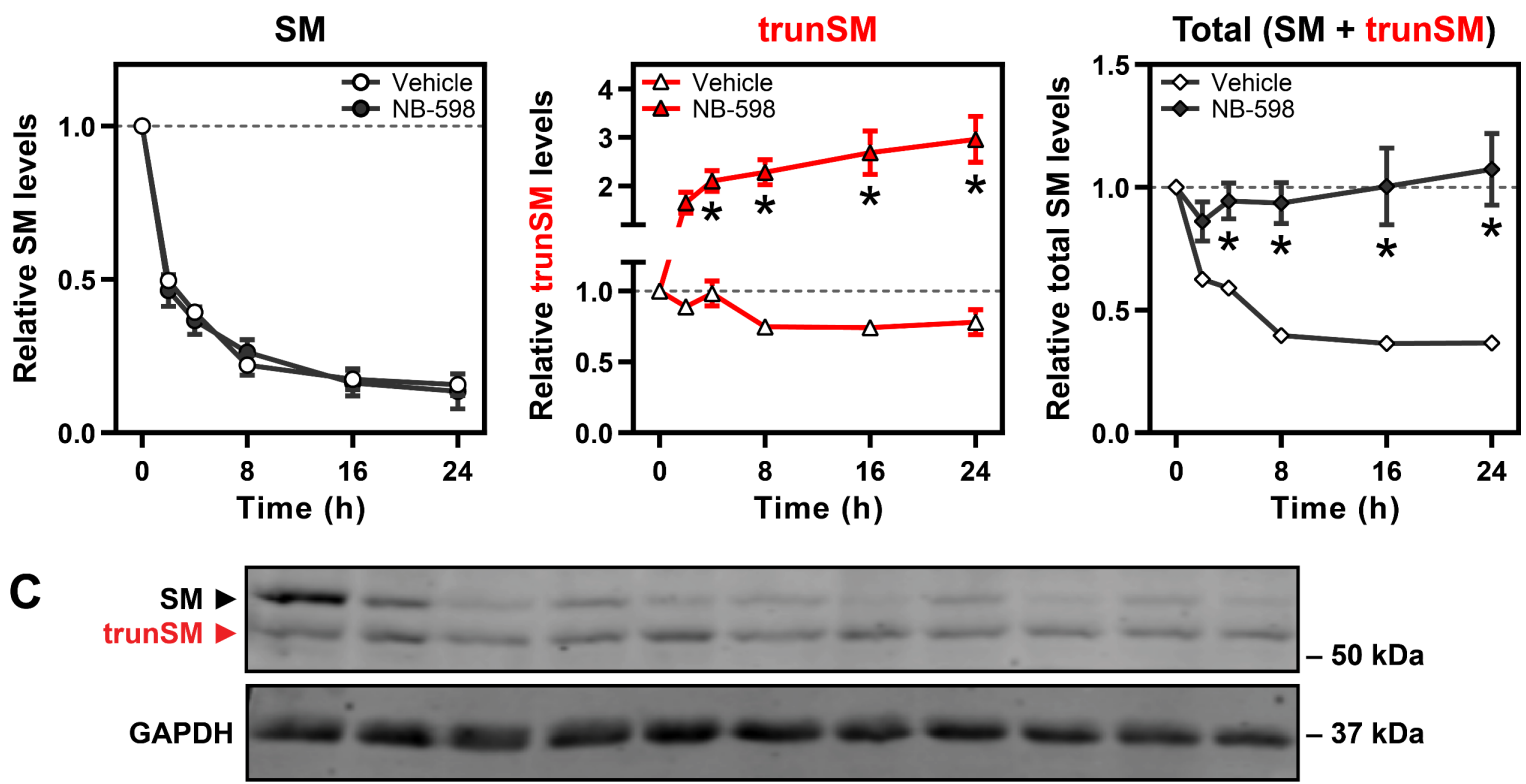

\begin{tabular}{|l|c|c|c|c|c|c|c|c|c|c|c|}
\hline Chol/CD & - & - & + & - & + & - & + & - & + & - & + \\
\hline Time (h) & 0 & \multicolumn{2}{|c|}{2} & \multicolumn{2}{|c|}{4} & \multicolumn{2}{|c|}{8} & \multicolumn{2}{|c|}{16} & 24 \\
\hline
\end{tabular}
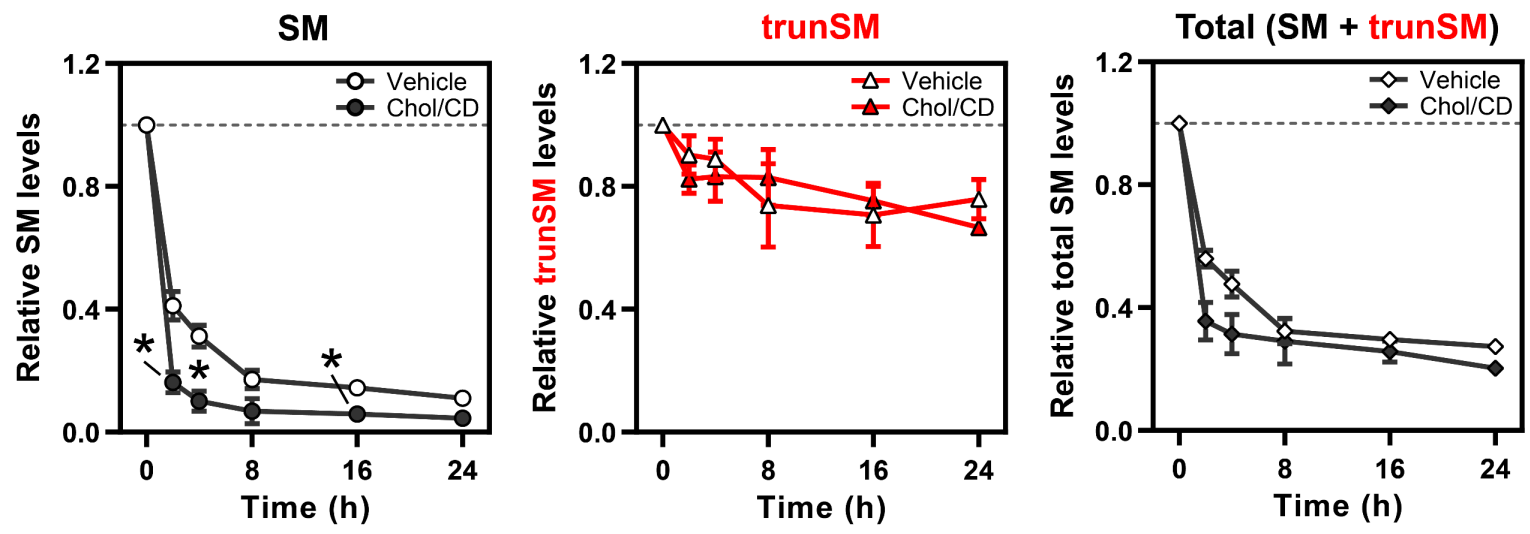


\section{Figure 1. A truncated, cholesterol-insensitive form of SM is present in a variety of cell types}

105 (A) The indicated cell lines were treated in the presence or absence of $1 \mu \mathrm{M} \mathrm{NB}-598$ for $8 \mathrm{~h}$, and 106 immunoblotting was performed for SM and truncated SM (trunSM, red). Immunoblots are 107 representative of $n \geq 3$ (HEK293T, HeLaT, Huh7, HepG2) or $n=1$ (Be(2)-C) independent 108 experiments.

109 (B, C) HEK293T cells were treated with $10 \mu \mathrm{g} / \mathrm{mL}$ cycloheximide in the presence or absence of 110 (B) $1 \mu \mathrm{M}$ NB-598 or (C) $20 \mu \mathrm{g} / \mathrm{mL}$ cholesterol-methyl- $\beta$-cyclodextrin complexes (Chol/CD) for 111 the indicated times. Graphs depict densitometric quantification of SM levels (left), trunSM levels 112 (center), or total SM levels (SM + trunSM; right) normalized to the $0 \mathrm{~h}$ timepoint, which was set 113 to 1 (dotted line). Data presented as mean $\pm \mathrm{SEM}$ from $n \geq 3$ independent experiments (*, $114 p \leq 0.05$; two-tailed paired $t$-test vs. vehicle condition). 
trunSM is not produced by alternative $S Q L E$ transcripts

The GENCODE- and RefSeq-annotated human genomes each predict a different proteincoding isoform of $S Q L E$. These isoforms utilize alternative first exons that substitute the coding sequence of the first 97 amino acids of full-length SM with a two- or 39-amino acid sequence, respectively (Fig. 2A). Given our hypothesis that trunSM lacks the SM-N100 domain, as well as the similarity between the apparent molecular weight of trunSM $(\sim 55 \mathrm{kDa})$ and the predicted molecular weights of the $S Q L E$ isoforms (53.1 kDa for the GENCODE isoform, trunSQLE1; and $57.6 \mathrm{kDa}$ for the RefSeq isoform, trunSQLE2), we sought to confidently rule out the possibility that trunSM arises from alternative $S Q L E$ transcripts.

To this end, we transfected HEK293T cells with siRNA targeting exon 9 of SQLE, which is present in all three $S Q L E$ isoforms (quantified collectively as totalSQLE), or exon 1 of the canonical SQLE isoform only (fullSQLE; Fig. 2A). Both siRNAs reduced trunSM protein levels (Fig. 2B) whereas trunSQLE1 mRNA expression was downregulated by only exon 9 siRNA, ruling out this isoform as giving rise to trunSM (Fig. 2C). Unexpectedly, trunSQLE2 mRNA expression was downregulated by exon 1 siRNA, perhaps due to the presence of the siRNA target sequence in an unannotated 3'-untranslated region of this transcript. To determine the likelihood of trunSQLE2 accounting for trunSM formation, we next performed absolute quantification of $S Q L E$ cDNA. Full-length $S Q L E$ cDNA comprised the great majority of $S Q L E$ transcripts $\left(\sim 1.6 \times 10^{7}\right.$ cDNA copies per $\mu$ g of reverse transcribed RNA), while trunSQLE1 and trunSQLE2 cDNA were less abundant by over two orders of magnitude $\left(\sim 8.0 \times 10^{4}\right.$ and $\sim 1.5 \times 10^{5}$ cDNA copies, respectively) (Fig. 2D). Given that (1) trunSM protein levels are comparable to full-length SM (Fig. 2B), (2) NB-598-induced accumulation of trunSM occurs in the presence of the protein synthesis inhibitor cycloheximide (Fig. 1B), and (3) we later found that ectopic SM also produces a trunSM-like fragment (Fig. 3A), we concluded that trunSM is highly unlikely to be derived from lowly-abundant $S Q L E$ isoforms. 
A

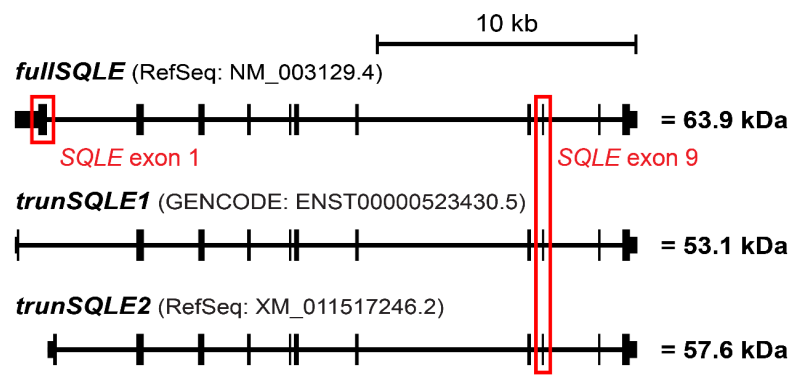

B

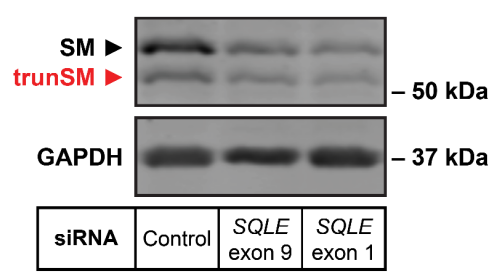

140 regions are indicated by red boxes.
C
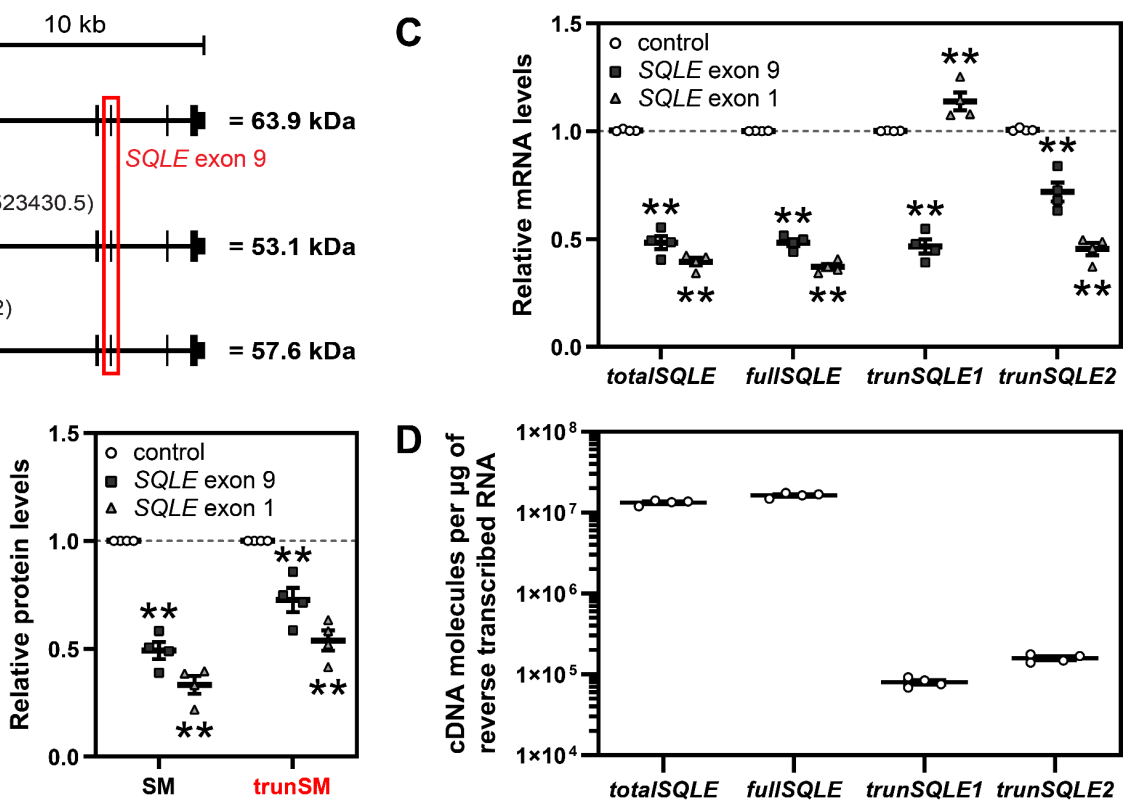

\section{Figure 2. trunSM is not produced by alternative $S Q L E$ transcripts}

(A) Schematic of full-length (fullSQLE) and alternative protein-coding (trunSQLE1, trunSQLE2) $S Q L E$ transcripts. Exons and untranslated regions are indicated by black bars and siRNA target

(B, C) HEK293T cells were transfected with the indicated siRNAs for $24 \mathrm{~h}$ and refreshed in maintenance medium for a further $24 \mathrm{~h}$. (B) Graph depicts densitometric quantification of SM and trunSM levels normalized to the control siRNA condition, which was set to 1 (dotted line). (C) SQLE transcript levels were normalized to $P B G D$ housekeeping transcript levels and adjusted relative to the control siRNA condition, which was set to 1 (dotted line).

(D) Absolute quantification of $S Q L E$ cDNA levels in control siRNA samples from (C).

(B, C, D) Data presented as mean \pm SEM from $n=4$ independent experiments, each performed in triplicate for qRT-PCR analysis $(* *, p \leq 0.01$; two-tailed paired $t$-test vs. control siRNA). 
To determine if trunSM is a proteolytic product of full-length SM, we transfected HEK293T cells with SM fused to N-terminal (HA) $)_{3}$ and C-terminal V5 epitope tags ([HA $]_{3}-\mathrm{SM}-$ V5). Immunoblotting detected two C-terminally-tagged proteins with molecular weights corresponding to SM and trunSM, the latter of which was stabilized by NB-598 (Fig. 3A). Only the full-length protein was N-terminally tagged, confirming that the trunSM-like fragment lacks the SM N-terminus. Interestingly, we were unable to recover a low-molecular weight, Nterminally tagged fragment, suggesting that the SM N-terminus undergoes complete proteolysis during truncation. To estimate the truncation site, we inserted a FLAG epitope tag at various positions within the (HA) $)_{3}-\mathrm{SM}-\mathrm{V} 5$ construct and monitored for its appearance in the truncated fragment. Truncation eliminated the FLAG tag when it was inserted after SM residue 60 but not residue 70 (Supplementary Fig. S2A), implying that truncation occurs between these two residues. Therefore, trunSM lacks part of the SM-N100 regulatory domain but retains the full C-terminal catalytic domain.

Given that SM truncation does not yield an intact N-terminal fragment (Fig. 3A), we hypothesized that trunSM formation requires the proteasome and, by extension, the ERAD of SM. ERAD effectors involved in the proteasomal degradation of SM include the AAA+-type ATPase VCP, the E3 ubiquitin ligase MARCHF6 and its associated E2 conjugating enzyme Ube2J2, and unidentified deubiquitinases [19, 21]. Treating HEK293T cells with VCP, proteasome or deubiquitinase inhibitors blocked the NB-598-induced accumulation of trunSM (Fig. 3B), confirming that a functional ERAD pathway and the proteasome are required for truncation. To corroborate this finding, we performed siRNA-mediated knockdown of ERAD effectors. Knockdown of $V C P$ similarly blunted the NB-598-induced accumulation of trunSM, whilst UBE2J2 or MARCHF6 knockdown had no effect (Fig. 3C, left). However, we noted that in the absence of NB-598, all three knockdowns had greatly reduced the basal truncation of SM (Fig. 3C, right; expressed as the ratio between trunSM and full-length SM levels). This suggested that while Ube2J2 and MARCHF6 are the major E2 and E3 proteins required for SM truncation under normal conditions, other proteins can compensate for their absence during NB-598-stimulated truncation. This contrasted with the apparent absolute requirement for VCP. A lysosome-dependent route for SM degradation has been proposed [9]; however, inhibitors of lysosomal acidification had no effect on trunSM formation (Supplementary Fig. S2B), further supporting an ERAD-dependent mechanism.

As ERAD requires substrate ubiquitination, we next sought to identify whether a 187 SM-N100 regulatory domain, given that SM is truncated at its N-terminus. While mutation of 188 Lys-82 and the published ubiquitination site Lys-90 [26] slightly reduced the truncation of the 189 (HA)3-SM-V5 construct, a more marked effect was observed upon combined mutation of the 190 Lys-82/90/100 cluster (Fig. 3D; Supplementary Fig. S2C), implying functional redundancy 191 amongst these residues. This reduction in truncation was not compounded by additional mutation 
192 of Lys-15/16, residues located nearer to the SM N-terminus, suggesting that Lys-82, Lys-90 and 193 Lys-100 are most critical for truncation. We previously showed that threonine, serine and 194 cysteine residues within SM-N100 contribute to the cholesterol-accelerated degradation of SM, 195 with Ser-83 serving as a non-canonical ubiquitination site [20] (Supplementary Fig. S2C). 196 However, mutating these residues did not affect truncation (Fig. 3D). Given that lysine residues 197 within the SM-N100 domain are not required for cholesterol-accelerated degradation of SM [5, 198 20], this indicated that the proteasomal truncation of SM depends on a distinct ubiquitin signal. 

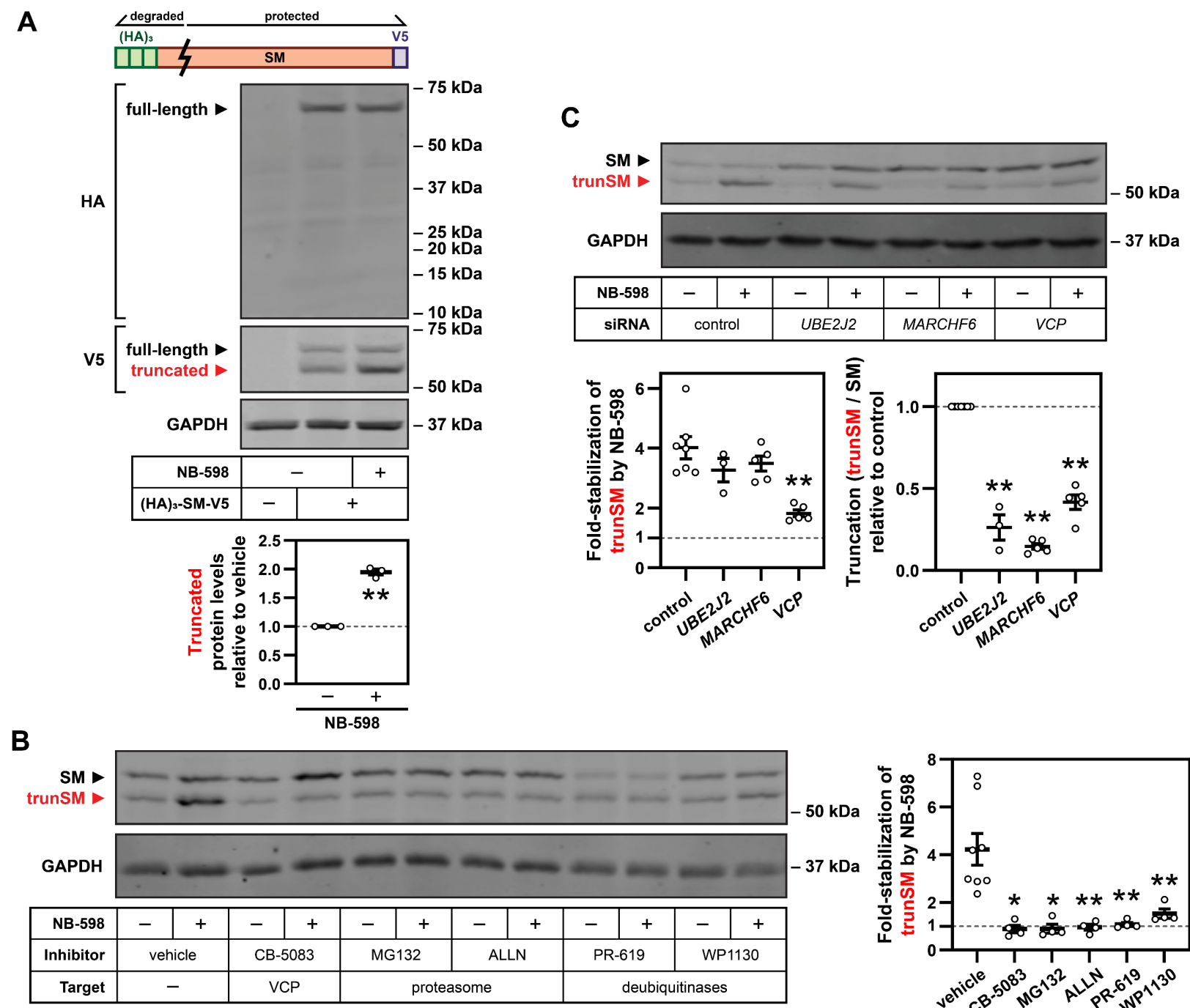

D
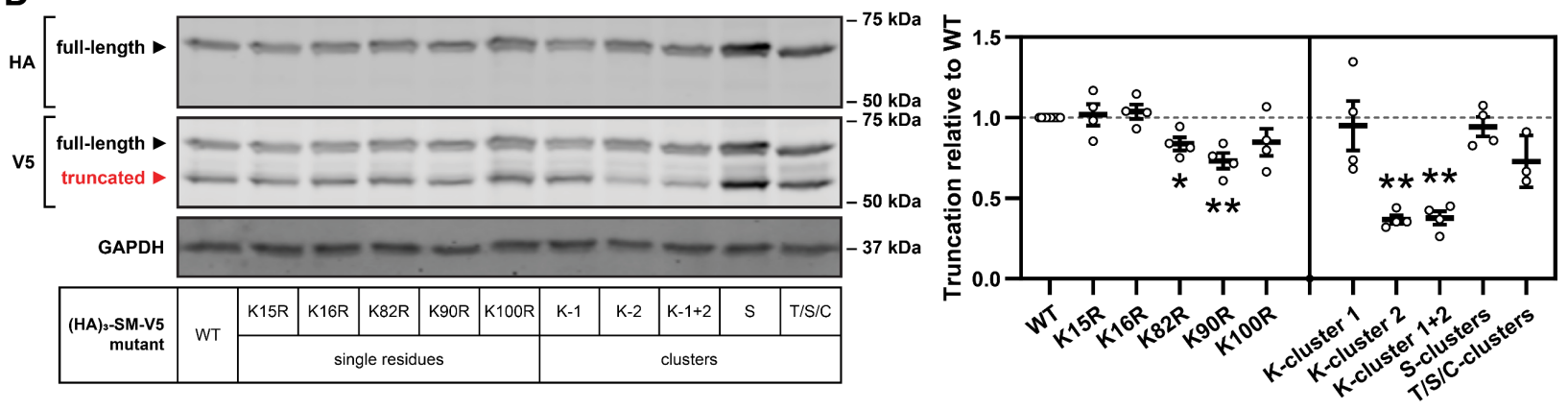
Figure 3. trunSM arises from partial proteasomal degradation of the SM N-terminus

(A) HEK293T cells were transfected with empty vector or pCMV-(HA) 3 -SM-V5 expression vector for $24 \mathrm{~h}$, refreshed in maintenance medium for $16 \mathrm{~h}$, and treated in the presence or absence of $1 \mu \mathrm{M}$ NB-598 for $8 \mathrm{~h}$. Lysates were separated by $4-15 \%$ gradient Tris-glycine SDSPAGE. Graph depicts densitometric quantification of truncated protein levels normalized to the vehicle condition, which was set to 1 (dotted line).

206 (B) HEK293T cells were treated with $5 \mu \mathrm{M}$ CB-5083, $20 \mu \mathrm{M}$ MG132, $25 \mu \mathrm{g} / \mathrm{mL}$ ALLN, $40 \mu \mathrm{M}$ PR-619 or $10 \mu \mathrm{M}$ WP1130, in the presence or absence of $1 \mu \mathrm{M}$ NB-598, for $8 \mathrm{~h}$. Graph depicts densitometric quantification of trunSM stabilization by NB-598.

209 (C) HEK293T cells were transfected with the indicated siRNAs for $24 \mathrm{~h}$, refreshed in 210 maintenance medium for $16 \mathrm{~h}$, and treated in the presence or absence of $1 \mu \mathrm{M} \mathrm{NB}-598$ for $8 \mathrm{~h}$. 211 Graphs depict densitometric quantification of (left) trunSM stabilization by NB-598, or (right) 212 SM truncation normalized to the control siRNA condition, which was set to 1 (dotted line).

213 (D) HEK293T cells were transfected with the indicated constructs for $24 \mathrm{~h}$ and refreshed in 214 maintenance medium for $24 \mathrm{~h}$. Graph depicts densitometric quantification of (HA) 3 -SM-V5 215 truncation normalized to the wild-type (WT) construct, which was set to 1 (dotted line). Cluster 216 mutations: K-cluster 1 (K15R, K16R); K-cluster 2 (K82R, K90R, K100R); K-cluster 1+2 217 (K15R, K16R, K82R, K90R, K100R); S-clusters (S59A, S61A, S83A, S87A); T/S/C-clusters 218 (T3A, T9A, T11A, S43A, C46A, S59A, S61A, S67A, S71A, S83A, S87A).

219 (A, B, C, D) Data presented as mean \pm SEM from $n \geq 3$ independent experiments $(*, p \leq 0.05$; $220 * *, p \leq 0.01$, two-tailed paired $t$-test vs. [A, B] vehicle, [C] control siRNA or [D] WT). 


\section{SM truncation depends on an intrinsically disordered region and the stability of the catalytic domain}

Few other substrates of partial proteasomal degradation are known. However, two features are associated with truncation: (1) a low-complexity sequence [27] or (2) high intrinsic disorder [28]. In both cases, the region must be adjacent to a tightly folded domain that is resistant to proteasomal unfolding and degradation, allowing an opportunity for substrate release [27-29]. To investigate whether these features could account for SM truncation, we analyzed the SM protein sequence using predictors of sequence complexity and intrinsic disorder. Four short regions of low sequence complexity were located throughout SM, including one within the SM-N100 domain (residues 51-62; Fig. 4A). Deletion of this region ( $\Delta 50-60)$ slightly reduced the truncation of the (HA) 3 -SM-V5 construct but did not alter the size of the truncated fragment (Supplementary Fig. S3A), further supporting the idea that truncation occurs after residue 60. More strikingly, we identified a highly intrinsically disordered region between residues 83-120 (Fig. 4A), adjacent to the predicted truncation site. By contrast, residues in the C-terminal direction of this region, comprising the SM catalytic domain, were highly ordered.

Supporting the importance of the disordered region in partial degradation of SM, its deletion $(\Delta 81-120)$ abolished truncation (Fig. 4B). Halving the length of the disordered region ( $\Delta 91-110)$ also prevented truncation, whilst tandem duplication of the disordered region (dup81120) had little effect, implying that a minimum length of intrinsic disorder is required for this process. We also noted that the apparent molecular weight of the truncated fragment increased when the disordered region was duplicated, suggesting that the truncation site remained unchanged despite the extended disorder length. As the region corresponding to residues 81-120 is highly disordered in SM orthologues from Chinese hamster, chicken, zebrafish and sea lamprey, despite their differing levels of sequence conservation (Fig. 4C, Supplementary Fig. S3B and S3C), we next tested the effect of substituting these regions into human SM. Truncation was maintained or even enhanced in constructs derived from Chinese hamster and chicken, and approximately halved in constructs derived from zebrafish and sea lamprey SM (Fig. 4C). The persistence of truncation in all four mutant constructs indicated that the intrinsically disordered nature of the 81-120 region is sufficient to promote truncation, although sequence-specific features may have an accessory function.

The proteasome typically engages and initiates degradation from intrinsically disordered regions of its substrates [30]. Therefore, we considered if residues 81-120 of SM are an internal proteasomal engagement site that results in preferential degradation of the N-terminus. A similar mechanism has been reported for other substrates of partial degradation [29]. To test this, we generated N-terminal fusions of SM with two proteins that impede proteasomal processivity: a 30-amino acid glycine-alanine repeat (GAr) from the Epstein-Barr virus nuclear antigen-1 [31], or dihydrofolate reductase (DHFR), which becomes tightly folded and resistant to degradation upon the binding of its ligand methotrexate [32]. We reasoned that if degradation were initiated internally, these fusions would not block truncation but rather protect the N-terminus from 
complete degradation. However, we found that the fusion of GAr sequences dramatically ablated truncation, and we were unable to recover N-terminal fragments of the expected molecular weight (10-15 kDa; Fig. 4D). Fusion of DHFR similarly reduced truncation, and its further stabilization by methotrexate did not rescue the $\mathrm{N}$-terminus from degradation. This indicated that partial proteasomal degradation of SM is initiated from the N-terminus rather than an internal site. To support this conclusion, we further manipulated the SM N-terminus by sequentially removing HA epitope tags from the (HA) $3-\mathrm{SM}-\mathrm{V} 5$ construct. These tags have a propensity for intrinsic disorder [33] and may enhance proteasomal engagement at the N-terminus. As expected, this led to a stepwise reduction in SM truncation (Supplementary Fig. S3D), confirming that truncation proceeds from the N-terminus.

All known examples of partial proteasomal degradation require a tightly folded domain adjacent to the truncation site. Given that the SM catalytic domain has a compact structure [34] and is predicted to be highly ordered (Fig. 4A), we considered the possibility that its stability is also essential for truncation. Supporting this idea was our earlier observation that NB-598 treatment rapidly accumulates trunSM (Fig. 1B). NB-598 is a potent, tight-binding inhibitor of SM that strongly stabilizes the catalytic domain [34], likely increasing its resistance to proteasomal unfolding. To examine the inverse situation, we generated point mutations within the catalytic domain based on the crystal structure of SM [34]. Our rationale was that nonconservative substitutions in the domain interior would be more destabilizing than conservative substitutions, which would in turn be more destabilizing than mutations on the domain exterior. As expected, most of the substitutions significantly reduced SM truncation, and those that were both internal and non-conservative tended to have a larger effect than those which were conservative or external (Fig. 4E). Of note, the non-conservative mutation of Tyr-195 (Y195A) ablated truncation to a greater extent than its conservative equivalent (Y195F). This strongly suggested that catalytic domain stability is required for partial degradation. Taken together, our disordered region and the stability of the SM catalytic domain. 
A

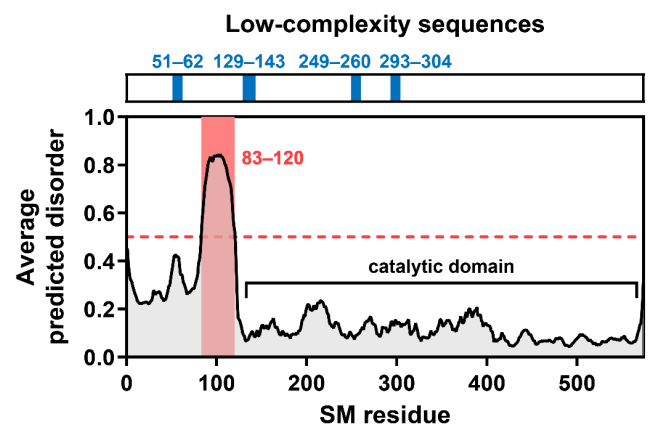

C

E
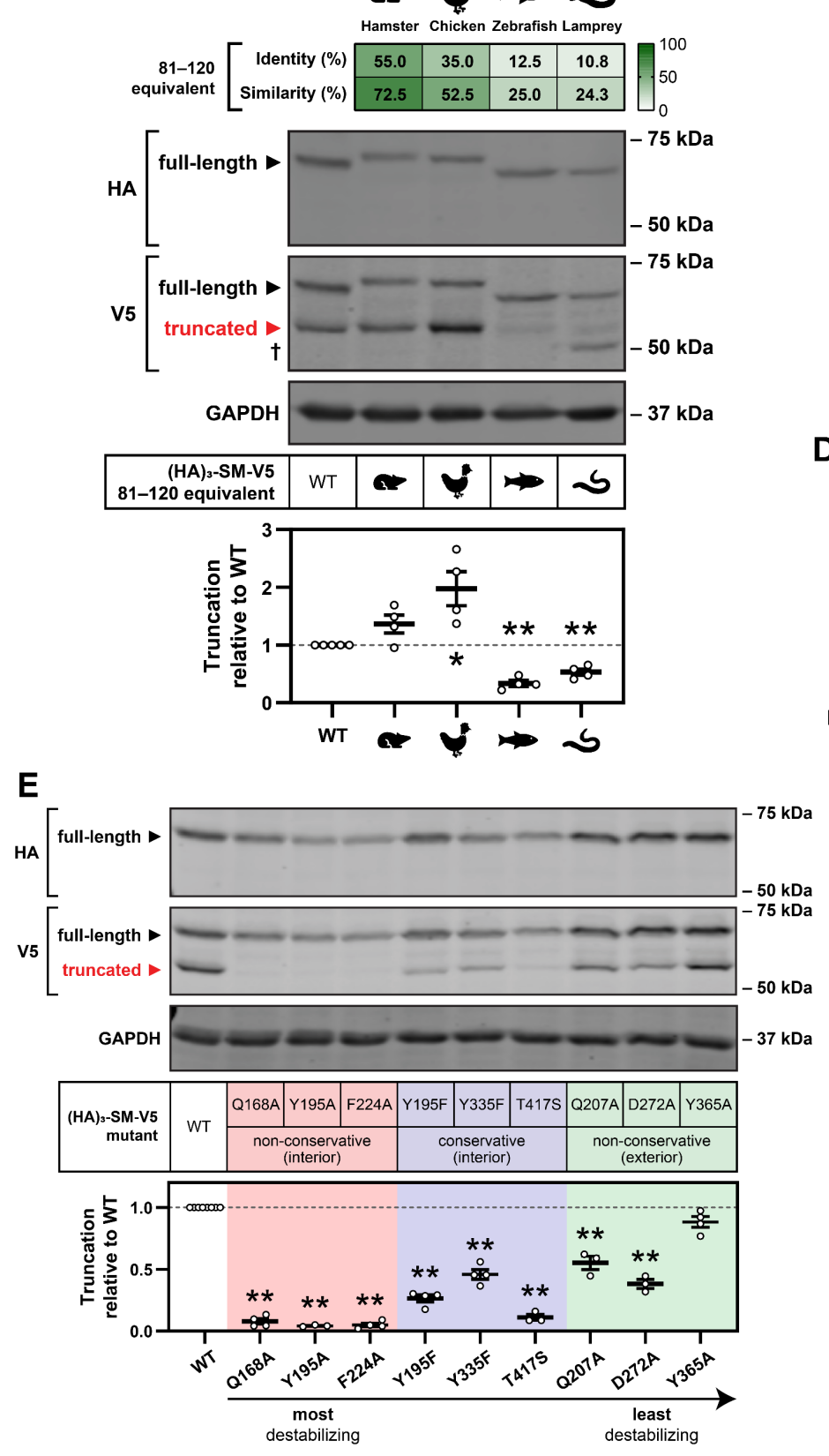

B
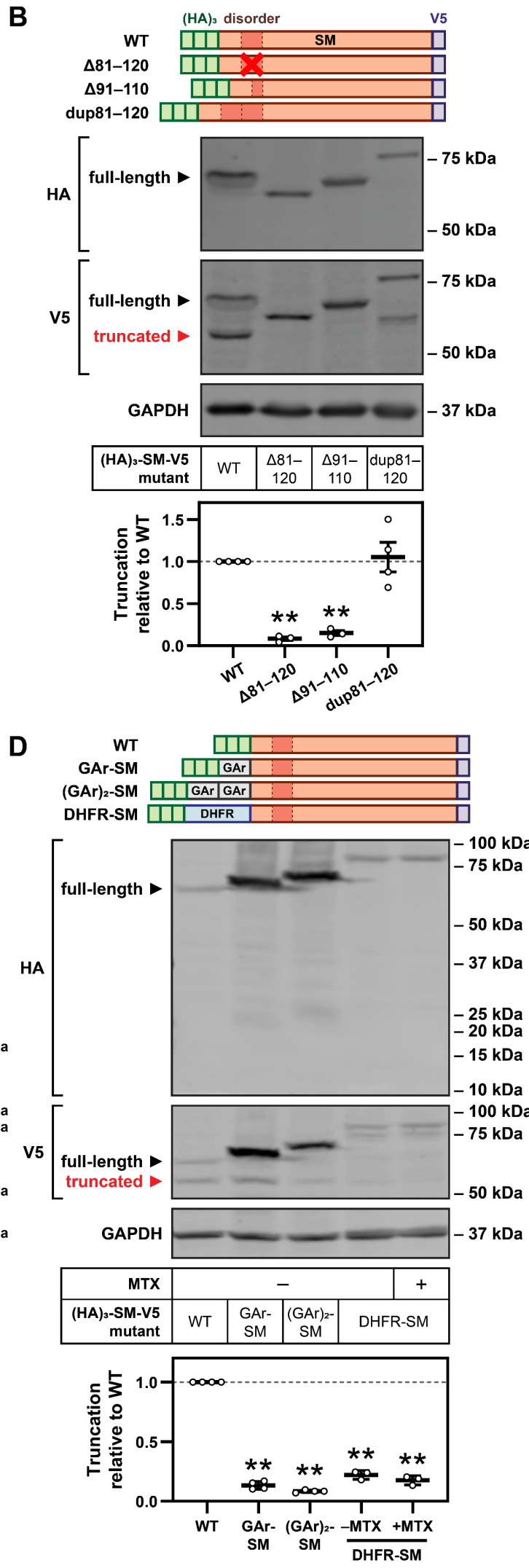

the catalytic domain

290 (A) Low-complexity regions (blue) and intrinsically disordered regions (red) within the SM 291 protein sequence.

292 (B, C, E) HEK293T cells were transfected with the indicated constructs for $24 \mathrm{~h}$ and refreshed in 293 maintenance medium for $24 \mathrm{~h}$. (C) Dagger indicates an additional non-trunSM fragment.

294 (D) HEK293T cells were transfected with the indicated constructs for $24 \mathrm{~h}$, refreshed in 295 maintenance medium for $16 \mathrm{~h}$, and treated in the presence or absence of $10 \mu \mathrm{M}$ methotrexate 296 (MTX) for $8 \mathrm{~h}$. Lysates were separated by 4-15\% gradient Tris-glycine SDS-PAGE.

297 (B - E) Graphs depict densitometric quantification of (HA) $)_{3}-\mathrm{SM}-\mathrm{V} 5$ truncation normalized to the 298 WT construct, which was set to 1 (dotted line). Data presented as mean \pm SEM from $n \geq 3$ 299 independent experiments ( ${ }^{*}, p \leq 0.05$; $^{* *}, p \leq 0.01$, two-tailed paired $t$-test vs. WT). 
trunSM adopts an altered ER membrane topology

The stability and cholesterol-resistance of trunSM (Fig. 1C), as well as the preservation

302 of the entire SM catalytic domain following truncation (Supplementary Fig. S2A), suggested that 303 it would act as a constitutively active form of SM. Previous studies have established that SM 304 lacking the SM-N100 domain retains catalytic activity [34, 35]; therefore, trunSM is highly 305 likely to be active. However, this is contingent on trunSM maintaining the ER localization of 306 full-length SM. Fractionation of HEK293T cell lysates revealed that like full-length SM [5], 307 trunSM is membrane-associated (Fig. 5A). However, a greater proportion of trunSM was found 308 in the cytoplasmic fraction compared with full-length SM, particularly in the absence of NB-598. 309 This suggested that trunSM is more loosely bound to the membrane than full-length SM, 310 possibly due to the loss of the SM-N100 re-entrant loop (residues $\sim 20-40$ ). To investigate this 311 further, membranes were isolated and treated with aqueous buffer (control), 1\% SDS 312 (solubilizing), $0.1 \mathrm{M} \mathrm{Na}_{2} \mathrm{CO}_{3}$ (high $\mathrm{pH}$ ) or $1 \mathrm{M} \mathrm{NaCl}$ (high salt). Solubilizing conditions disrupt 313 the membrane association of all membrane proteins, while high-pH or high-salt conditions 314 release peripheral membrane proteins (in the latter case, those associated via electrostatic 315 interactions) [36, 37]. Both full-length SM and trunSM remained membrane-associated under 316 aqueous or high-salt conditions and were released into the supernatant fraction under solubilizing 317 conditions (Fig. 5B). A similar distribution was observed for SM-N100-GFP-V5, a fusion 318 construct that includes the SM-N100 re-entrant loop [18]. However, unlike full-length SM and 319 SM-N100-GFP-V5, the membrane association of trunSM was readily disrupted by high-pH 320 conditions. This suggested that the loss of the SM-N100 re-entrant loop renders trunSM a 321 peripheral ER membrane protein. 
A

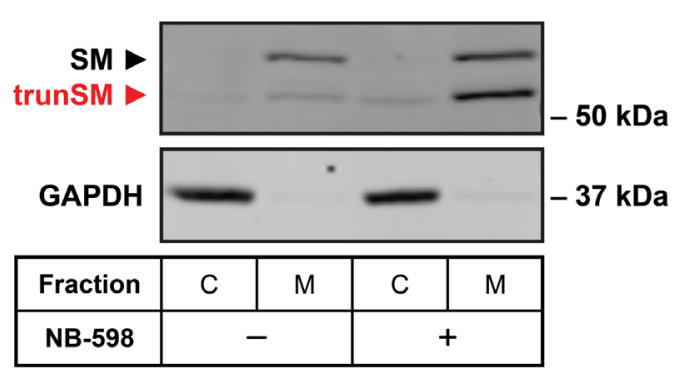

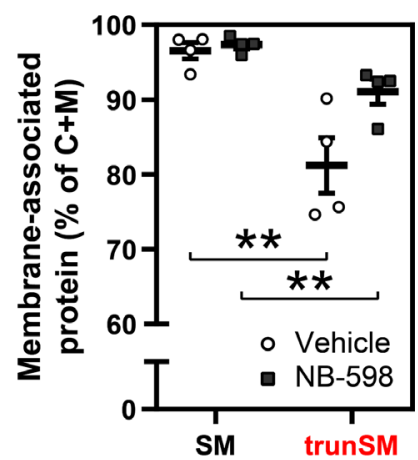

\section{B}

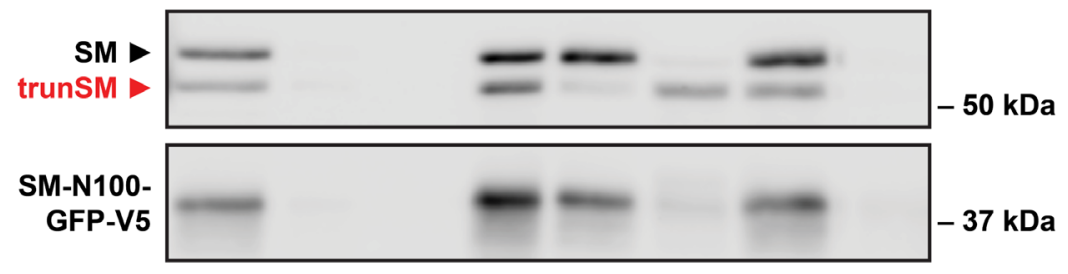

\begin{tabular}{|c|c|c|c|c|c|c|c|c|}
\hline Fraction & $\mathrm{P}$ & $\mathrm{S}$ & $\mathrm{P}$ & $\mathrm{S}$ & $\mathrm{P}$ & $\mathrm{S}$ & $\mathrm{P}$ & $\mathrm{S}$ \\
\hline Buffer & aqueous & $\begin{array}{c}\text { solubilizing } \\
(1 \% \mathrm{SDS})\end{array}$ & $\begin{array}{c}\text { high pH } \\
\left(0.1 \mathrm{M} \mathrm{Na}_{2} \mathrm{CO}_{3}\right)\end{array}$ & $\begin{array}{c}\text { high salt } \\
(1 \mathrm{M} \mathrm{NaCl})\end{array}$ \\
\hline
\end{tabular}

\section{Figure 5. trunSM adopts an altered ER membrane topology}

324 (A) HEK293T cells were treated in the presence or absence of $1 \mu \mathrm{M} \mathrm{NB}-598$ for $8 \mathrm{~h}$, and 325 cytosolic $(\mathrm{C})$ or membrane $(\mathrm{M})$ fractions were isolated. Graph depicts the proportion of overall 326 protein $(\mathrm{C}+\mathrm{M})$ found in the membrane fraction. Data presented as mean \pm SEM from $n=4$ 327 independent experiments $(* *, p \leq 0.01$, two-tailed paired $t$-test vs. SM).

328 (B) HEK293T cells were transfected with pTK-SM-N100-GFP-V5 for $24 \mathrm{~h}$ and refreshed in maintenance medium for a further $24 \mathrm{~h}$. Membrane fractions were isolated and treated as

330 indicated, followed by collection of pellet $(\mathrm{P})$ and supernatant $(\mathrm{S})$ fractions. Immunoblot is 331 representative of $n=3$ independent experiments. 


\section{Discussion}

333

334

335

336

337

338

Feedback regulation of SM protein levels is conferred by its lipid-sensing SM-N100 domain, which contains structural elements required for cholesterol-accelerated degradation. In this study, we characterized a truncated form of SM (trunSM) that is produced by partial proteolysis of the SM-N100 domain. This renders trunSM long-lived, cholesterol-resistant, and, as the SM-N100 domain is not required for catalysis [34, 35], constitutively active. Truncation requires ERAD and the proteasome and depends on two features of SM: intrinsic disorder within the 81-120 region and the stability of the adjacent catalytic domain. Furthermore, the loss of a membrane-embedded region at the $\mathrm{N}$-terminus causes trunSM to adopt a peripheral association with the ER membrane. These findings establish a new mechanism affecting the abundance and activity of SM, with likely consequences for the homeostatic control of cholesterol synthesis.

\section{Proteasomal truncation of SM}

The SM-N100 domain contains two cholesterol-sensing elements that enable its accelerated degradation: a re-entrant loop spanning residues $\sim 15-40$ that undergoes a conformational change in the presence of excess cholesterol [18], and a membrane-associated amphipathic helix from residues 62-73 that deforms and is ejected from the ER membrane under similar conditions [17]. Truncation of the SM N-terminus eliminates the SM-N100 re-entrant loop and likely disrupts the conformation and function of the nearby amphipathic helix, accounting for the longevity and cholesterol-resistance of the trunSM fragment (Fig. 1C). This reinforces the importance of these two structural features for the metabolic regulation of fulllength SM, as they have largely been studied only in the context of the isolated SM-N100 domain $[17,18]$. Loss of the membrane-embedded re-entrant loop also renders trunSM a peripheral membrane protein (Fig. 5B), bound to the ER membrane via two C-terminal helices [34]. Proteomic studies have shown that SM partitions to lipid droplets [38, 39], and it is possible that the peripheral membrane association of trunSM makes it more suited to the lipid droplet monolayer than its full-length counterpart. This possibility warrants further consideration given the predicted constitutive activity of trunSM and the lipid droplet localization of lanosterol synthase, the cholesterol synthesis enzyme immediately downstream of SM [38, 39].

Using pharmacological and genetic approaches we found that the truncation of SM, like its cholesterol-regulated degradation [5], occurs through proteasomal ERAD and requires Ube2J2, MARCHF6 and VCP (Fig. 3B and 3C; Fig. 6). However, the exact mechanism is distinct. Truncation is not stimulated by cholesterol (Fig. 1C), depends on a cluster of lysine residues (Lys-82/90/100) that is dispensable for cholesterol regulation [5, 20], and is independent of atypical cholesterol-dependent ubiquitination sites within SM-N100 (Fig. 3D) [20]. Instead, truncation may occur for a subset of SM molecules undergoing a basal degradation route. This is supported by our finding that upon stabilization of SM by NB-598, complete degradation ceases and all SM molecules become truncated (Fig. 1B). Indeed, truncation may be a relatively rare 
event in the absence of NB-598, but the dramatically different stabilities of full-length and truncated SM lead to an equilibrium where their protein levels are comparable. Combined with the saturation of ERAD machinery, this may explain why overexpressed SM-V5 is less truncated than endogenous SM (Supplementary Fig. S3D) despite the two proteins having identical Ntermini. Along similar lines, we previously found that overexpressed SM exhibits blunted

374 cholesterol regulation [5].

A

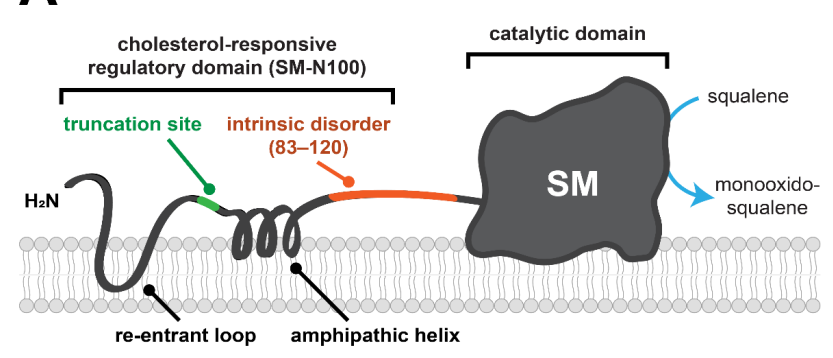

C

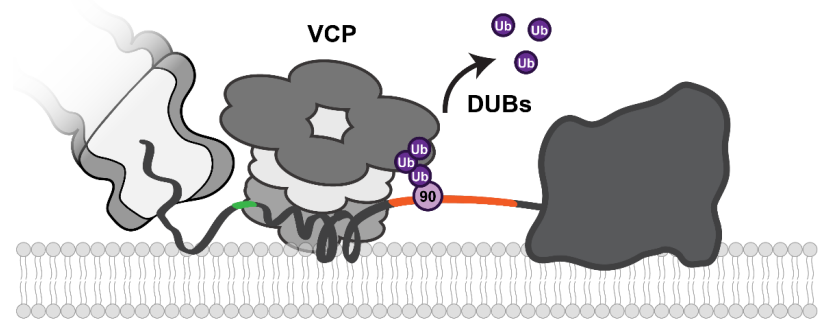

B

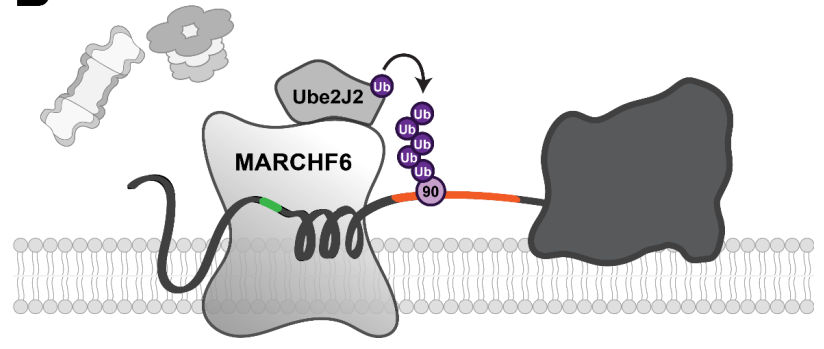

D

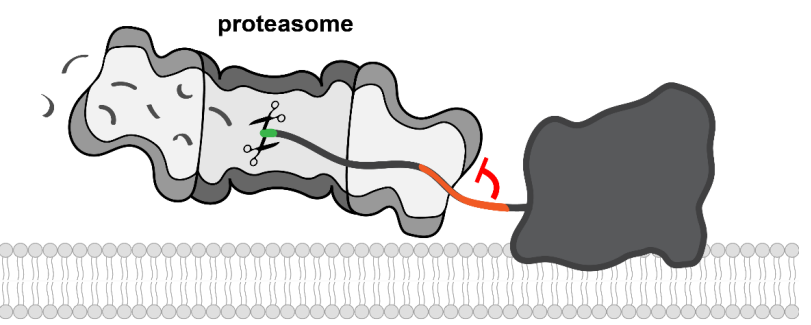

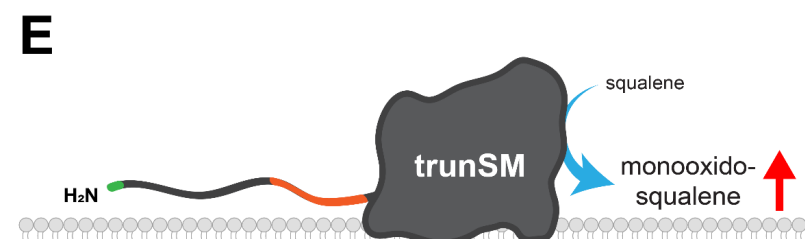

Figure 6. Model for the mechanism of SM truncation

377 (A) Full-length SM comprises the SM-N100 regulatory domain, containing a cholesterol-sensing re-entrant loop and amphipathic helix, and the C-terminal catalytic domain that converts squalene to monooxidosqualene. (B) Ube2J2 and MARCHF6 ubiquitinate the SM-N100 domain, likely at the known ubiquitination site Lys-90. (C) VCP is recruited to ubiquitinated SM and extracts the SM-N100 domain from the ER membrane, enabling the proteasome to begin degrading SM from its N-terminus. Deubiquitinases (DUBs) are required for this process. (D) The SM 81-120 disordered region impedes unfolding of the adjacent catalytic domain by the proteasome, preventing further degradation. (E) The undegraded portion of SM (trunSM) is released from the proteasome. The loss of part of the SM-N100 regulatory domain renders trunSM resistant to cholesterol-induced degradation, and therefore constitutively active. 
The membrane association of trunSM (Fig. 5A) implies that the proteasome acts on SM directly at the ER without the need for cytosolic chaperones. While proteasomal recruitment to the ER has been described, this is generally in the context of interaction with the Sec61 translocon to export and degrade misfolded polypeptides [40]. One notable exception is the degradation of the yeast cadmium exporter Pcalp, in which interaction between the ubiquitinated substrate and the proteasome requires Doa10p (the orthologue of MARCHF6) and is bridged by Cdc48p (the orthologue of VCP) [41]. A similar pathway may be required for the truncation of $\mathrm{SM}$, and presumably extends to its basal or even cholesterol-accelerated degradation. Precedent for the latter is found in the sterol-induced degradation of Hmg2p and its mammalian equivalent HMGCR (another rate-limiting enzyme of cholesterol synthesis), which also involves direct interaction with the proteasome at the ER membrane [41, 42]. In the case of SM, the AAA+ ATPase VCP likely provides the driving force to extract the membrane-associated components of the SM-N100 domain for degradation, although MARCHF6 may also contribute given the retrotranslocase function of Doa10p [43]. The role of deubiquitinases in SM truncation is less well-defined, but may involve the removal of ubiquitin chains from the Lys-82/90/100 cluster to facilitate processing by VCP or entry into the proteasome [44, 45]. Ubiquitination of two or more of these residues is seemingly required for maximal truncation (Fig. 3D), which may explain why a peptide containing Lys-90 alone was not enriched in a study that used VCP inhibition to accumulate and capture ERAD substrates [46]. Interestingly, proteasomal substrates with K63linked ubiquitin chains are degraded less efficiently than those with the more typical K48linkages [47], but whether SM is modified in this way is unknown.

\section{Structural determinants of truncation}

In establishing SM as a substrate of partial proteasomal degradation, we identify the first eukaryotic enzyme known to be truncated in this manner. Of the few other reported substrates, almost all are soluble transcription factors and only two occur in mammalian cells: NFאB subunit p105 [24] and the Hedgehog signaling transducer Gli3 [25, 48]. Proteasomal truncation may be activating or inhibitory, depending on the substrate. In the case of $\mathrm{NF \kappa B}$, the proteasome degrades an inhibitory domain that sequesters the protein to the cytoplasm, thereby enabling its nuclear translocation [49]. Conversely, the transactivation domain of Gli3 is degraded to yield a dominant-negative repressor [25]. In yeast, partial degradation of Spt23p and Mga2p liberates them from the ER membrane to activate lipogenic gene expression, with Spt23p processing repressed by fatty acids [50]. Proteasomal processing can also have profound consequences at the organismal level: truncation of Gli3 or the Drosophila proteins Lola29M and Shavenbaby regulates processes including sex determination, differentiation, and stem cell maintenance [25, 28, 51, 52]. Like these examples, the truncation of SM eliminates a regulatory region (cholesterol-sensing elements of the SM-N100 domain) and yields a fragment with altered properties (constitutive activity and a peripheral membrane association). 
For most truncation substrates, including NFкB [53], Gli3 [54] and Def1p [55], partial degradation requires a two-part signal: a low-complexity sequence (such as a glycine- or glutamine-rich region) and an adjacent tightly folded domain. The $19 \mathrm{~S}$ regulatory particle of the proteasome is thought to poorly transduce an unfolding force when occupied by a lowcomplexity sequence, preventing disassembly of the folded domain and allowing substrate escape [27, 56]. However, we ruled out a low-complexity sequence as a major determinant of SM truncation (Supplementary Fig. S3A). Unique mechanisms have been described for the remaining substrates, with the exception of Lola29M where the structural features enabling truncation are unknown [51]. Spt23p and Mga2p are truncated upon proteasomal engagement at an internal hairpin loop, which leads to preferential degradation of the C-terminus rather than the tightly-folded N-terminal domain [29]. Such a mechanism is unlikely to control SM truncation, which is initiated at the N-terminus (Fig. 4D). In the case of Shavenbaby, a large ( 550 residue) intrinsically disordered domain comprising its degraded portion is juxtaposed with high predicted order in the adjacent, undegraded domain [28]. This most closely resembles SM, where truncation depends on the disordered 81-120 region (Fig. 4B), but the much shorter length of this region clearly represents a distinct signal.

On the other hand, the presence of a tightly folded and degradation-resistant domain is essential for all known examples of partial degradation. SM is no exception, and changes to the stability of its catalytic domain (via NB-598 binding or disruptive point mutations) are closely correlated with truncation (Fig. 1B and 4E). The split-domain structure of SM, in which substrate- and cofactor-binding regions are interspersed throughout the primary sequence [34], may contribute to a compact conformation that is unusually resistant to unfolding and degradation. Proximity of the catalytic domain to the ER membrane is presumably required for its interaction with the hydrophobic substrate squalene, and may sterically hinder engagement by VCP or the proteasome. Our findings thus reinforce the importance of a stable domain for disrupting proteasomal processivity, while also establishing a unique counterpart in the bipartite truncation signal: the 81-120 disordered region.

How does the $81-120$ region promote truncation? The distance from the center of the proteasomal $20 \mathrm{~S}$ core particle to the edge of the 19S regulatory particle is $\sim 200 \AA$ [57], equivalent to $\sim 60$ residues of a fully extended polypeptide chain. Therefore, as proteasomal degradation of SM reaches the predicted truncation site between residues 60 and 70 (Supplementary Fig. S2A), the 81-120 region is translocating through the regulatory particle and the catalytic domain is on the periphery of the complex. The conspicuous spacing of these three elements suggests that the 81-120 region is a proteasomal 'stop signal' that impedes further unfolding and incorporation of SM, analogous to the low-complexity sequences of other substrates (Fig. 6). This may explain why a minimum length of disorder is required for truncation (Fig. 4B), as well as the need for both the disordered region and catalytic domain stability. Without the former, the proteasome successfully transduces the force necessary to unfold the catalytic domain, and without the latter, proteasomal ATPases are still capable of 
disassembling the catalytic domain in their weakened state. In both cases, complete degradation is the result (Fig. 4B and 4E). It is noteworthy that the SM truncation site is unaltered when residues on the N-terminal side of the disorder are removed (Supplementary Fig. S3A) or when the disorder is duplicated (Fig. 4B), which supports the idea that the proteasome releases trunSM upon first encountering the $81-120$ region.

Ubiquitination within residues $81-120$ is unlikely to be solely responsible for its effect on truncation, given that the lowly truncated $\Delta 91-110$ mutant (Fig. 4B) retains both Lys-82 and Lys-90. Likewise, Lys-90 and Lys-100 are not conserved in highly truncated hamster and chicken orthologues (Fig. 4C). One possibility is that these sequences contain other lysine residues that serve as alternative ubiquitination sites. However, the number of lysine residues within orthologous regions (Supplementary Fig. S3B) does not correlate with the extent of truncation, and partial degradation is observed for a lamprey-derived sequence containing only one lysine residue. This strongly suggests that the intrinsically disordered nature of the region promotes truncation, but further work is required to elucidate the precise mechanism. Interestingly, the partial degradation of $\mathrm{Spt} 23 \mathrm{p}$ and $\mathrm{NF}-\kappa \mathrm{B}$ is augmented by their homodimerization with a full-length counterpart, which protects the rescued fragment from complete proteolysis $[58,59]$. Disordered regions often provide an interface for protein-protein interaction [60], and so a similar process may control SM truncation. It is currently unknown if $\mathrm{SM}$ forms dimers in vivo, but the transmembrane microprotein CASIMO1 is a confirmed interactor of SM [61] and GSK-3 $\beta$ was recently reported to associate with the isolated SM-N100 domain [62]. Given that GSK-3 $\beta$ is a soluble protein and much of SM-N100 is membraneassociated, the hydrophilic 81-100 region is a strong candidate for a binding site. Both CASIMO1 and GSK-3 $\beta$ are linked with metabolism $[61,63]$, warranting study into whether they impact on the production of the constitutively active trunSM.

\section{Consequences for cholesterol synthesis}

Levels of full-length SM and trunSM are generally comparable across a range of human cell types (Fig. 1A), indicating that two enzyme pools are maintained: one which is subject to metabolic regulation and another which is constitutively active. As SM is a rate-limiting enzyme of cholesterol synthesis, this may establish a baseline level of pathway flux that can be fine-tuned depending on cholesterol availability. It is striking that amongst distant vertebrate orthologues of $\mathrm{SM}$, there is strong structural conservation of the intrinsically disordered region (Supplementary

494 Fig. S3B) and sequence conservation within the catalytic domain [5]. Truncation of SM occurs in 495 CHO-7 cells (Supplementary Fig. S1) and may be characteristic of higher eukaryotes. Here, the 496 basal activity of trunSM would permit a steady-state level of cholesterol synthesis to better meet 497 the demands of multicellular organisms. conditions of cholesterol excess, which would otherwise delay the eventual resumption of 
cholesterol synthesis or lead to dramatic accumulation of the substrate squalene [5]. Whilst previously considered a hydrocarbon intermediate with few biochemical properties, squalene is protective against cell death induced by lipid peroxidation [11] yet cytotoxic when it is unable to be effectively sequestered to lipid droplets $[10,64]$. Increased squalene levels also accompany the dermal and gastrointestinal side effects of pharmacological SM inhibition in mammals [12]. Therefore, a persistent population of trunSM may be advantageous in clearing excess squalene and reducing its aberrant accumulation. Along similar lines, squalene itself stabilizes SM by binding to the SM-N100 domain and blunting its cholesterol-accelerated degradation [15]. It remains to be determined if squalene also influences the truncation of SM, given that both processes depend on MARCHF6 (Fig. 3C) [15]. It is also conceivable that trunSM is relevant in pathophysiological contexts, given that dysregulation of cholesterol synthesis is implicated in hepatocellular carcinoma [9] and prostate cancer [65]. However, this possibility awaits future investigation.

\section{Materials and methods}

\section{Reagents and cell lines}

Fetal calf serum (FCS), newborn calf serum (NCS), high-glucose Dulbecco's Modified Eagle's Medium (DMEM-HG), Roswell Park Memorial Institute 1640 medium (RPMI), DMEM/Ham's Nutrient Mixture F-12 (DF-12), penicillin/streptomycin, Opti-MEM reduced serum medium, RNAiMAX transfection reagent, Lipofectamine 3000 transfection reagent, TRI reagent, and the SuperScript III First-Strand Synthesis kit were from Thermo-Fisher (Carlsbad, CA, US). Lipoprotein-deficient serum (LPDS) was prepared from NCS as described previously [8]. Primers, small interfering RNA (siRNA), protease inhibitor cocktail, and Tween-20 were from Sigma-Aldrich (St Louis, MO, US). The SensiMix SYBR No-ROX kit was from Bioline (London, UK). SmaI was from New England Biolabs (Ipswich, MA, US). Tris-glycine SDSPAGE gels were prepared in-house. Immobilon Western chemiluminescent HRP substrate and nitrocellulose membranes were from Millipore (Burlington, MA, US). The QIAquick PCR purification kit was from Qiagen (Hilden, GE). TransIT-2020 was from Mirus Bio (Madison, WA, US). Phosphate-buffered saline (PBS) was from UNSW (Sydney, AU). Skim milk powder was from Fonterra (Richmond, VIC, AU), and bovine serum albumin was from Bovogen Biologicals (Keilor, VIC, AU). Chemicals were from the following suppliers: cycloheximide (Sigma-Aldrich C7698), NB-598 (Chemscene CS-1274), cholesterol complexed with methyl- $\beta$-cyclodextrin (Chol/CD) (Sigma-Aldrich C4951), CB-5083 (Cayman Chemical

533 (Cayman Chemical Company 16276), WP1130 (Cayman Chemical Company 15277), 534 ammonium chloride (Ajax Finechem 31), bafilomycin A1 (Sigma-Aldrich B1793), methotrexate 535 (Cayman Chemical Company 13960), Tris-(hydroxy)methylamine (Ajax Finechem 2311), 
sodium chloride (Ajax Finechem 465); sodium dodecyl sulfate (Sigma-Aldrich 75746), magnesium chloride (Ajax Finechem 296), hydrochloric acid (Ajax Finechem 256), HEPES (Sigma-Aldrich 54457), potassium hydroxide (Ajax Finechem 405), potassium chloride (Ajax Finechem, 383), sodium ethylenediaminetetraacetic acid (Ajax Finechem 180), sodium ethylene glycol-bis( $\beta$-aminoethyl ether)-N,N,N',N'-tetraacetic acid (Sigma-Aldrich E8145), sodium carbonate (Ajax Finechem 463), polyethyleneimine (Sigma-Aldrich 03880), glycine (Ajax 542 Finechem 1083), methanol (Ajax Finechem 318), dimethyl sulfoxide (Ajax Finechem 2225),

543 Ponceau S solution (Sigma-Aldrich P7170), glycerol (Ajax Finechem 242), bromophenol blue 544 (Sigma-Aldrich B0126), $\beta$-mercaptoethanol (Sigma-Aldrich M3148).

HEK293T cells were a gift from the UNSW School of Medical Sciences (UNSW, Sydney NSW, Australia), HepG2 and Huh7 cells were gifts from the Centre for Cardiovascular Research (UNSW, Sydney NSW, Australia), Be(2)-C and HeLaT cells were gifts from Drs. Louise Lutze-Mann and Noel Whitaker (UNSW, Sydney NSW, Australia), and CHO-7 cells were a gift from Drs. Joseph Goldstein and Michael Brown (UT Southwestern Medical Center, Dallas TX, USA).

\section{Cell culture}

Cells were maintained in a humidified incubator at $37^{\circ} \mathrm{C}$ and $5 \% \mathrm{CO}_{2}$ in maintenance medium (DMEM-HG [HEK293T, HepG2, Huh7, Be(2)-C], RPMI [HeLaT] or DF-12 [CHO-7]; $10 \%[\mathrm{v} / \mathrm{v}] \mathrm{FCS}$ for human cells or $5 \%[\mathrm{v} / \mathrm{v}]$ LPDS $[50 \mathrm{mg} / \mathrm{mL}$ protein] for CHO-7 cells; $100 \mathrm{U} / \mathrm{mL}$ penicillin; $100 \mu \mathrm{g} / \mathrm{mL}$ streptomycin). To improve HEK293T and HepG2 surface adhesion, culture vessels were treated with $25 \mu \mathrm{g} / \mathrm{mL}$ polyethyleneimine in phosphate-buffered saline (PBS) for $15 \mathrm{~min}$ prior to cell seeding. Plasmid and siRNA transfections were performed in maintenance medium lacking penicillin and streptomycin. For all treatments, appropriate solvent controls were used (water [Chol/CD, ammonium chloride]; dimethyl sulfoxide [cycloheximide, NB-598, CB-5083, MG132, ALLN, bafilomycin A1, PR-619, WP1130, methotrexate]) and the final concentration of dimethyl sulfoxide did not exceed $0.2 \%(\mathrm{v} / \mathrm{v})$ in cell culture medium. Treatments were delivered in full medium refreshes, and all experiments were a total of $72 \mathrm{~h}$ in duration.

\section{Plasmids}

A pcDNA3.1/V5-His TOPO expression vector (Invitrogen) encoding the protein-coding sequence of human SM (NM_003129.4) fused with three N-terminal HA tags, a C-terminal

567 linker sequence, and C-terminal V5 and $6 \times$ His tags ([HA $\left.]_{3}-\mathrm{SM}-\mathrm{V} 5\right)$ was generated previously 568 in our laboratory by Dr Julian Stevenson. Codon-optimized nucleotide sequences encoding 569 orthologues of human SM-N100 were previously obtained from GenScript [7], and sequences 570 encoding orthologues of human SM residues 101-120 were derived using the Integrated DNA 
Technologies codon optimization tool. Domain insertions and deletions within the (HA) 3 -SM-V5 construct were generated using the polymerase-incomplete primer extension cloning method and sequence- and ligation-independent cloning method [5, 6], and domain and nucleotide substitutions were generated using the overlap extension cloning method [4], as described previously [9]. To generate standards for the absolute quantification of mRNA levels, qRT-PCR products were amplified from HEK293T cDNA and inserted into the pGL3-Basic vector (Promega) using the overlap extension cloning method [4]. The identity of all plasmids was confirmed via Sanger dideoxy sequencing. The plasmids used in this study are listed in Table S1, and the primer sequences used for DNA cloning are listed in Table S2.

\section{siRNA and plasmid transfection}

To downregulate gene expression or transiently overexpress SM-derived constructs, cells were seeded into 12-well plates. The next day, cells were transfected with 15 pmol siRNA using RNAiMAX (Invitrogen; $15 \mathrm{pmol}$ siRNA : $2 \mu \mathrm{L}$ reagent) or $1 \mu \mathrm{g}$ expression vector using Lipofectamine 3000 (Invitrogen; $1 \mu \mathrm{g}$ DNA : $2 \mu \mathrm{L}$ reagent with $2 \mu \mathrm{L}$ P3000 supplemental reagent), delivered in Opti-MEM. After $24 \mathrm{~h}$, cells were refreshed in maintenance medium, treated as specified in figure legends, and harvested $48 \mathrm{~h}$ after transfection. The siRNAs used in this study are listed in Table S1.

\section{Protein harvest, SDS-PAGE and immunoblotting}

To quantify protein levels, cells were seeded into 12 -well plates and treated as specified in figure legends. Total protein was harvested in 2\% SDS lysis buffer $(10 \mathrm{mM}$ Tris-HCl $[\mathrm{pH} 7.6], 2 \%[\mathrm{w} / \mathrm{v}] \mathrm{SDS}, 100 \mathrm{mM} \mathrm{NaCl})$ containing $2 \%$ [v/v] protease inhibitor cocktail, passed 20 times through a 21-gauge needle, and vortexed for $20 \mathrm{~min}$. Lysate protein content was quantified using the bicinchoninic acid assay (Thermo-Fisher), and sample concentrations were normalized by dilution in $2 \%$ SDS lysis buffer and $1 \times$ Laemmli buffer $(50 \mathrm{mM}$ Tris-HCl $[\mathrm{pH} 6.8], 2 \%[\mathrm{w} / \mathrm{v}]$ SDS, 5\% [v/v] glycerol, 0.04\% [w/v] bromophenol blue, 1\% [v/v] $\beta$-mercaptoethanol). Samples were heated at $95^{\circ} \mathrm{C}$ for $5 \mathrm{~min}$ and separated by $10 \%(\mathrm{w} / \mathrm{v})$ Trisglycine SDS-PAGE, unless otherwise specified in figure legends. Proteins were electroblotted onto nitrocellulose membranes and blocked in 5\% skim milk powder (Diploma) in PBS with $0.1 \%(\mathrm{v} / \mathrm{v})$ Tween-20 (PBST), or in 5\% bovine serum albumin in PBST for FLAG detection. Immunoblotting was performed using rabbit polyclonal anti-SM(SQLE) (Proteintech 12544-1-AP; $1: 2,500$ at $4^{\circ} \mathrm{C}$ for $16 \mathrm{~h}$ ), rabbit monoclonal anti-GAPDH (Cell Signaling Technology $2118 ; 1: 2,500$ at $4^{\circ} \mathrm{C}$ for $16 \mathrm{~h}$ ), rabbit monoclonal anti-HA (Cell Signaling Technology $3724 ; 1: 2,000$ at $4^{\circ} \mathrm{C}$ for $16 \mathrm{~h}$ ), mouse monoclonal anti-V5 (Invitrogen R960-25; 1:5,000 at room temperature for $1 \mathrm{~h}$ ), rabbit polyclonal anti-FLAG (Millipore F7425; 1:10,000 at $4^{\circ} \mathrm{C}$ for $16 \mathrm{~h}$ ), IRDye 680RD donkey anti-rabbit IgG (LI-COR Biosciences LCR-926-68073; $1: 5,000$ [SM detection] or 1:10,000 at room temperature for $1 \mathrm{~h}$ ), IRDye $800 \mathrm{CW}$ donkey anti- 
mouse IgG (LI-COR Biosciences LCR-926-32212; 1:10,000 at room temperature for $1 \mathrm{~h}$ ), peroxidase-conjugated AffiniPure donkey anti-rabbit IgG (Jackson ImmunoResearch Laboratories 711-035-152; 1:10,000 at room temperature for $1 \mathrm{~h}$ ), and peroxidase-conjugated AffiniPure donkey anti-mouse IgG (Jackson ImmunoResearch Laboratories 715-035-150; 1:10,000 at room temperature for $1 \mathrm{~h}$ ). All antibodies were diluted in 5\% bovine serum albumin in PBST, except for anti-FLAG and peroxidase-conjugated antibodies, which were diluted in 5\% skim milk in PBST. Fluorescence-based detection of SM, GAPDH, HA and V5 was performed using an Odyssey Clx imager (LI-COR Biosciences), and enhanced chemiluminescence-based detection of FLAG was performed using Immobilon Western chemiluminescent HRP substrate (Millipore) and an ImageQuant LAS 500 imager (Cytiva Life Sciences). Due to low protein

617 levels following differential solubilization of microsomal membranes, enhanced 618 chemiluminescence was used to detect FLAG and V5 in these samples. Densitometry analysis of

\section{RNA harvest and qRT-PCR}

To quantify squalene epoxidase ( $S Q L E$ ) gene expression, cells were seeded in triplicate into 12-well plates and transfected with siRNA as specified in figure legends. Total RNA was harvested using TRI reagent (Sigma-Aldrich) and polyadenylated RNA was reverse transcribed using the SuperScript III First Strand Synthesis kit (Invitrogen). cDNA products were used as the template for quantitative reverse transcription-PCR (qRT-PCR) using the SensiMix SYBR No-ROX kit (Bioline). For relative quantification of gene expression, mRNA levels were normalized to the porphobilinogen deaminase ( $P B G D$ ) housekeeping gene using the comparative $\mathrm{C}_{\mathrm{T}}$ method [10] and adjusted relative to the control siRNA condition, as specified in figure legends. For absolute quantification of SQLE expression, plasmids containing qPCR amplicon sequences were linearized by digestion with SmaI for $1 \mathrm{~h}$ and purified using the QIAquick PCR purification kit (Qiagen). Linearized plasmids were quantified using spectrophotometry, serially diluted in nuclease-free water to concentrations of between $\sim 5 \times 10^{2}$ and $\sim 5 \times 10^{8}$ target copies $/ \mu \mathrm{L}$ and used as the template for $\mathrm{qPCR}$ in triplicate as described above. A standard curve of $\log$ (target sequence copies) vs. $\mathrm{C}_{\mathrm{T}}$ value was generated and compared with $\mathrm{C}_{\mathrm{T}}$ values from cDNA samples to quantify gene expression. Data were expressed in units of cDNA molecules per $\mu \mathrm{g}$ of reverse transcribed RNA. The primer sequences used for qRT-PCR in this study are listed in Table S2.

\section{Cell fractionation and differential solubilization}

To examine protein membrane association, cells were seeded into $10 \mathrm{~cm}$ dishes and treated as specified in figure legends. Microsomal membranes were isolated as described in [11] 641 with some modifications. Briefly, cells were scraped in cold PBS, pelleted at $1,000 \times \mathrm{g}$ and $4^{\circ} \mathrm{C}$ 642 for $5 \mathrm{~min}$, and lysed in $500 \mu \mathrm{l}$ buffer F1 (10 mM HEPES-KOH [pH 7.4], $10 \mathrm{mM} \mathrm{KCl,} 1.5 \mathrm{mM}$ 
$643 \mathrm{MgCl}_{2}, 5 \mathrm{mM}$ sodium EDTA, $5 \mathrm{mM}$ sodium EGTA, $250 \mathrm{mM}$ sucrose, 2\% [v/v] protease 644 inhibitor cocktail). Lysates were centrifuged at $1,000 \times g$ and $4^{\circ} \mathrm{C}$ for $10 \mathrm{~min}$, and the 645 supernatant was centrifuged at $20,000 \times g$ and $4^{\circ} \mathrm{C}$ for $30 \mathrm{~min}$. The $20,000 \times g$ supernatant was 646 collected and designated the cytosolic fraction. The $20,000 \times g$ pellet was resuspended in $100 \mu 1$ 647 buffer F2 (10 mM Tris-HCl [pH 7.4], $100 \mathrm{mM} \mathrm{NaCl}, 1 \%$ [w/v] SDS, 2\% [v/v] protease inhibitor 648 cocktail) and designated the membrane fraction. Protein content was quantified using the 649 bicinchoninic acid assay (Thermo-Fisher), and sample concentrations were normalized by 650 dilution in buffer F1 or buffer F2, plus $1 \times$ Laemmli buffer, for immunoblotting analysis.

To determine the peripheral or integral nature of protein membrane association, differential solubilization of microsomal membranes was performed as described in [11] with some modifications. Briefly, cells were seeded into $14.5 \mathrm{~cm}$ dishes and transfected with $40 \mu \mathrm{g}$ pTK-SM-N100-GFP-V5 expression vector using TransIT-2020 (Mirus Bio; $1 \mu \mathrm{g}$ DNA: $2 \mu \mathrm{L}$ reagent), delivered in Opti-MEM. After $24 \mathrm{~h}$, cells were refreshed in maintenance medium for a further $24 \mathrm{~h}$, and microsomal membranes were isolated as described above. Equivalent volumes of membrane preparations $(20 \mu \mathrm{l})$ were treated with $200 \mu \mathrm{l}$ buffer F1, 1\% (w/v) SDS (with $10 \mathrm{mM}$ Tris- $\mathrm{HCl}$ [pH 7.4]), $0.1 \mathrm{M} \mathrm{Na}_{2} \mathrm{CO}_{3}(\mathrm{pH} 11.5$ ), or $1 \mathrm{M} \mathrm{NaCl}$ (with $10 \mathrm{mM}$ Tris-HCl [pH 7.4]), and incubated at $4^{\circ} \mathrm{C}$ with end-over-end mixing for $30 \mathrm{~min}$. Mixtures were then centrifuged at $20,000 \times g$ and $4^{\circ} \mathrm{C}$ for $30 \mathrm{~min}$. The soluble supernatant fraction was collected, and the insoluble pellet fraction was resuspended in $200 \mu 1$ buffer F3 (buffer F1 containing $100 \mathrm{mM} \mathrm{NaCl}$ ). Equal volumes of supernatant and pellet fractions were mixed with $1 \times$ Laemmli buffer for immunoblotting analysis.

\section{Sequences and alignments}

DNA sequences of protein-coding SQLE isoforms (fullSQLE, NM_003129.4; trunSQLE1, ENST00000523430.5; trunSQLE2, XM_011517246.2) were obtained from the 667 RefSeq- (GRCh38.p13 109.20200228) and GENCODE-annotated (GRCh38.p13 668 GCA_000001405.28) human genomes. Protein sequences of human SM (Homo sapiens, 669 Q14534), Chinese hamster SM (Cricetulus griseus, A0A3L7IPT3), chicken SM (Gallus gallus, A0A1D5NWK3), zebrafish SM (Danio rerio, F1QDN5), sea lamprey SM (Petromyzon marinus, S4R6S3) and yeast Erg1p (Saccharomyces cerevisiae, P32476) were obtained from the UniProt database [12]. Protein sequence complexity was predicted using the SEG [13], CAST [14] and fLPS [15] algorithms, and regions identified by all three tools were defined as low-complexity

674 sequences. Protein intrinsic disorder was predicted using the online tools SPOT-dis2 [16], 675 MFDp2 [17], AUCpreD [18], IUPred2A [19], DISOPRED3 [20], PrDOS [21] and DisProt 676 (VL2E) [22], and residues with an average intrinsic disorder probability of $>0.5$ were defined as 677 intrinsically disordered. Protein sequence alignments were generated using Geneious Basic 678 v2020.1 (Biomatters Ltd.) with a BLOSUM62 cost matrix. 


\section{Data analysis and presentation}

Data were normalized as described in figure legends. Data visualization and statistical testing were performed using GraphPad Prism v8.4 (GraphPad Software Inc.) as specified in

682 figure legends. Thresholds for statistical significance were defined as: ${ }^{*}, p \leq 0.05 ; * *, p \leq 0.01$.

683 Schematics and figures were assembled using Adobe Illustrator v24.1 (Adobe Inc.).

\section{Acknowledgements}

685

We thank Dr Julian Stevenson for generating the pCMV-(HA) 3 -SM-V5 plasmid used in this study, Dr Ngee Kiat (Jake) Chua for insightful discussions, and the members of the Brown laboratory for critically reviewing this manuscript. This work was supported by Australian

688 Research Council Grant DP170101178 and a NSW Health Investigator Development Grant. H.W.C. is a recipient of an Australian Research Training Program scholarship.

\section{Competing interests}

The authors declare that there are no competing interests associated with the manuscript.

\section{References}

693 1. Ikonen, E. (2008) Cellular cholesterol trafficking and compartmentalization. Nat. Rev. Mol. Cell Biol. $694 \quad 9,125-138$

2. Prospective Studies Collaboration (2007) Blood cholesterol and vascular mortality by age, sex, and

3. Kuzu, O. F., Noory, M. A., and Robertson, G. P. (2016) The role of cholesterol in cancer. Cancer Res. deaths. Lancet. 370, 1829-1839

4. Howe, V., Sharpe, L. J., Alexopoulos, S. J., Kunze, S. V, Chua, N. K., Li, D., and Brown, A. J. (2016)

6. Belter, A., Skupinska, M., Giel-Pietraszuk, M., Grabarkiewicz, T., Rychlewski, L., and Barciszewski, J. (2011) Squalene monooxygenase - A target for hypercholesterolemic therapy. Biol. Chem. 392, $1053-1075$ 
with clinical relevance in breast cancer. Sci. Rep. 6, 19435

8. Stopsack, K. H., Gerke, T. A., Sinnott, J. A., Penney, K. L., Tyekucheva, S., Sesso, H. D., Andersson, S.-O. O., Cerhan, R., Giovannucci, E. L., Mucci, L. A., Rider, J. R., Andrén, O., Cerhan, J. R., Giovannucci, E. L., Mucci, L. A., and Rider, J. R. (2016) Cholesterol metabolism and prostate cancer lethality. Cancer Res. 76, 4785-4790

9. Liu, D., Wong, C. C., Fu, L., Chen, H., Zhao, L., Li, C., Zhou, Y., Zhang, Y., Xu, W., Yang, Y., Wu, B., Cheng, G., Lai, P. B.-S., Wong, N., Sung, J. J., and Yu, J. (2018) Squalene epoxidase drives NAFLD-induced hepatocellular carcinoma and is a direct pharmaceutical target. Sci. Transl. Med. 10, eaap9840

10. Mahoney, C. E., Pirman, D., Chubukov, V., Sleger, T., Hayes, S., Fan, Z. P., Allen, E. L., Chen, Y., Huang, L., Liu, M., Zhang, Y., McDonald, G., Narayanaswamy, R., Choe, S., Chen, Y., Gross, S., Cianchetta, G., Padyana, A. K., Murray, S., Liu, W., Marks, K. M., Murtie, J., Dorsch, M., Jin, S., Nagaraja, N., Biller, S. A., Roddy, T., Popovici-Muller, J., and Smolen, G. A. (2019) A chemical biology screen identifies a vulnerability of neuroendocrine cancer cells to SQLE inhibition. Nat. Commun. 10, 96

11. Garcia-Bermudez, J., Baudrier, L., Bayraktar, E. C., Shen, Y., La, K., Guarecuco, R., Yucel, B., Fiore, D., Tavora, B., Freinkman, E., Chan, S. H., Lewis, C., Min, W., Inghirami, G., Sabatini, D. M., and Birsoy, K. (2019) Squalene accumulation in cholesterol auxotrophic lymphomas prevents oxidative cell death. Nature. 567, 118-122

12. Nagaraja, R., Olaharski, A., Narayanaswamy, R., Mahoney, C., Pirman, D., Gross, S., Roddy, T. P., Popovici-Muller, J., Smolen, G. A., and Silverman, L. (2020) Preclinical toxicology profile of squalene epoxidase inhibitors. Toxicol. Appl. Pharmacol. 401, 115103

13. Horton, J. D., Shah, N. A., Warrington, J. A., Anderson, N. N., Park, S. W., Brown, M. S., and Goldstein, J. L. (2003) Combined analysis of oligonucleotide microarray data from transgenic and knockout mice identifies direct SREBP target genes. Proc. Natl. Acad. Sci. U. S. A. 100, 12027-12032

14. Howe, V., Sharpe, L. J., Prabhu, A. V, and Brown, A. J. (2017) New insights into cellular cholesterol acquisition: promoter analysis of human HMGCR and SQLE, two key control enzymes in cholesterol synthesis. Biochim. Biophys. Acta - Mol. Cell Biol. Lipids. 1862, 647-657

15. Yoshioka, H., Coates, H. W., Chua, N. K., Hashimoto, Y., Brown, A. J., and Ohgane, K. (2020) A key mammalian cholesterol synthesis enzyme, squalene monooxygenase, is allosterically stabilized by its substrate. Proc. Natl. Acad. Sci. 117, 7150-7158

16. Nathan, J. A. (2020) Squalene and cholesterol in the balance at the ER membrane. Proc. Natl. Acad. Sci. 117, 8228-8230

17. Chua, N. K., Howe, V., Jatana, N., Thukral, L., and Brown, A. J. (2017) A conserved degron containing an amphipathic helix regulates the cholesterol-mediated turnover of human squalene monooxygenase, a rate-limiting enzyme in cholesterol synthesis. J. Biol. Chem. 292, 19959-19973

18. Howe, V., Chua, N. K., Stevenson, J., and Brown, A. J. (2015) The regulatory domain of squalene monooxygenase contains a re-entrant loop and senses cholesterol via a conformational change. $J$. Biol. Chem. 290, 27533-27544

19. Zelcer, N., Sharpe, L. J., Loregger, A., Kristiana, I., Cook, E. C., Phan, L., Stevenson, J., and Brown, A. J. A. J. (2014) The E3 ubiquitin ligase MARCH6 degrades squalene monooxygenase and affects 3hydroxy-3-methyl-glutaryl coenzyme A reductase and the cholesterol synthesis pathway. Mol. Cell. Biol. 34, 1262-1270 
20. Chua, N. K., Hart-Smith, G., and Brown, A. J. (2019) Non-canonical ubiquitination of the cholesterolregulated degron of squalene monooxygenase. J. Biol. Chem. 294, 8134-8147

21. Chua, N. K., Scott, N. A., and Brown, A. J. (2019) Valosin-containing protein mediates the ERAD of squalene monooxygenase and its cholesterol-responsive degron. Biochem. J. 476, 2545-2560

22. Stevenson, J., Luu, W., Kristiana, I., and Brown, A. J. (2014) Squalene mono-oxygenase, a key enzyme

23. Honsho, M., Dorninger, F., Abe, Y., Setoyama, D., Ohgi, R., Uchiumi, T., Kang, D., Berger, J., and Fujiki, Y. (2019) Impaired plasmalogen synthesis dysregulates liver X receptor-dependent transcription

24. Fan, C.-M., and Maniatis, T. (1991) Generation of p50 subunit of NF-kB by processing of p105

25. Wang, B., Fallon, J. F., and Beachy, P. A. (2000) Hedgehog-regulated processing of Gli3 produces an

26. Hornbeck, P. V., Zhang, B., Murray, B., Kornhauser, J. M., Latham, V., and Skrzypek, E. (2015)

27. Tian, L., Holmgren, R. A., and Matouschek, A. (2005) A conserved processing mechanism regulates the activity of transcription factors Cubitus interruptus and NF-кB. Nat. Struct. Mol. Biol. 12, 10451053

28. Zanet, J., Benrabah, E., Li, T., Pélissier-Monier, A., Chanut-Delalande, H., Ronsin, B., Bellen, H. J., Payre, F., and Plaza, S. (2015) Pri sORF peptides induce selective proteasome-mediated protein processing. Science. 349, 1356-1358

29. Piwko, W., and Jentsch, S. (2006) Proteasome-mediated protein processing by bidirectional degradation initiated from an internal site. Nat. Struct. Mol. Biol. 13, 691-697

30. Prakash, S., Tian, L., Ratliff, K. S., Lehotzky, R. E., and Matouschek, A. (2004) An unstructured initiation site is required for efficient proteasome-mediated degradation. Nat. Struct. Mol. Biol. doi: $10.1038 / \mathrm{nsmb} 814$

31. Levitskaya, J., Sharipo, A., Leonchiks, A., Ciechanover, A., and Masucci, M. G. (1997) Inhibition of ubiquitin/proteasome-dependent protein degradation by the Gly-Ala repeat domain of the Epstein-Barr virus nuclear antigen 1. Proc. Natl. Acad. Sci. U. S. A. 94, 12616-12621

32. Johnston, J. A., Johnson, E. S., Waller, P. R. H., and Varshavsky, A. (1995) Methotrexate inhibits proteolysis of dihydrofolate reductase by the N-end rule pathway. J. Biol. Chem. doi: $10.1074 / j b c .270 .14 .8172$

33. Georgieva, M. V., Yahya, G., Codó, L., Ortiz, R., Teixidó, L., Claros, J., Jara, R., Jara, M., Iborra, A., Gelpí, J. L., Gallego, C., Orozco, M., and Aldea, M. (2015) Inntags: Small self-structured epitopes for innocuous protein tagging. Nat. Methods. 12, 955-958

34. Padyana, A. K., Gross, S., Jin, L., Cianchetta, G., Narayanaswamy, R., Wang, F., Wang, R., Fang, C., Lv, X., Biller, S. A., Dang, L., Mahoney, C. E., Nagaraja, N., Pirman, D., Sui, Z., Popovici-Muller, J., and Smolen, G. A. (2019) Structure and inhibition mechanism of the catalytic domain of human squalene epoxidase. Nat. Commun. 10, 97

35. Laden, B. P., Tang, Y., and Porter, T. D. (2000) Cloning, heterologous expression, and enzymological characterization of human squalene monooxygenase. Arch. Biochem. Biophys. 374, 381-388 
36. Feramisco, J. D., Goldstein, J. L., and Brown, M. S. (2004) Membrane topology of human Insig-1, a protein regulator of lipid synthesis. J. Biol. Chem. 279, 8487-8496

37. Fujiki, Y., Hubbard, L., Fowler, S., and Lazarow, P. B. (1982) Isolation of intracellular membranes by means of sodium carbonate treatment: Application to Endoplasmic Reticulum. J. Cell Biol. 93, 97-102

38. Pataki, C. I., Rodrigues, J., Zhang, L., Qian, J., Efron, B., Hastie, T., Elias, J. E., Levitt, M., and Kopito, R. R. (2018) Proteomic analysis of monolayer-integrated proteins on lipid droplets identifies amphipathic interfacial $\alpha$-helical membrane anchors. Proc. Natl. Acad. Sci. 115, E8172-E8180

39. Bersuker, K., Peterson, C. W. H. W. H., To, M., Sahl, S. J. J., Savikhin, V., Grossman, E. A. A., Nomura, D. K. K., and Olzmann, J. A. A. (2018) A proximity labeling strategy provides insights into the composition and dynamics of lipid droplet proteomes. Dev. Cell. 44, 97-112

40. Ng, W., Sergeyenko, T., Zeng, N., Brown, J. D., and Römisch, K. (2007) Characterization of the proteasome interaction with the Sec61 channel in the endoplasmic reticulum. J. Cell Sci. 120, 682-691

41. Smith, N., Adle, D. J., Zhao, M., Qin, X., Kim, H., and Lee, J. (2016) Endoplasmic reticulumassociated degradation of Pcalp, a polytopic protein, via interaction with the proteasome at the membrane. J. Biol. Chem. 291, 15082-15092

42. Morris, L. L., Hartman, I. Z., Jun, D. J., Seemann, J., and A. DeBose-Boyd, R. (2014) Sequential actions of the AAA-ATPase valosin-containing protein (VCP)/p97 and the proteasome 19S regulatory particle in sterol-accelerated, endoplasmic reticulum (ER)- associated degradation of 3-hydroxy-3methylglutarylcoenzyme A reductase. J. Biol. Chem. 289, 19053-19066

43. Schmidt, C. C., Vasic, V., and Stein, A. (2020) Doa10 is a membrane protein retrotranslocase in ERassociated protein degradation. Elife. 9, e56945

44. Ernst, R., Mueller, B., Ploegh, H. L., and Schlieker, C. (2009) The otubain YOD1 is a deubiquitinating enzyme that associates with p97 to facilitate protein dislocation from the ER. Mol. Cell. 36, 28-38

45. Yao, T., and Cohen, R. E. (2002) A cryptic protease couples deubiquitination and degradation by the proteasome. Nature. 419, 403-407

46. Huang, E. Y., To, M., Tran, E., Dionisio, L. T. A., Cho, H. J., Baney, K. L. M., Pataki, C. I., and Olzmann, J. A. (2018) A VCP inhibitor substrate trapping approach (VISTA) enables proteomic profiling of endogenous ERAD substrates. Mol. Biol. Cell. 29, 1021-1030

47. Reichard, E. L., Chirico, G. G., Dewey, W. J., Nassif, N. D., Bard, K. E., Millas, N. E., and Kraut, X. D. A. (2016) Substrate ubiquitination controls the unfolding ability of the proteasome. J. Biol. Chem. 291, 18547-18561

48. Chen, C. H., Von Kessler, D. P., Park, W., Wang, B., Ma, Y., and Beachy, P. A. (1999) Nuclear trafficking of Cubitus interruptus in the transcriptional regulation of Hedgehog target gene expression. Cell. 98, 305-316

49. Blank, V., Kourilsky, P., and Israël, A. (1991) Cytoplasmic retention, DNA binding and processing of the NF-kappa B p50 precursor are controlled by a small region in its C-terminus. EMBO J. 10, 41594167

50. Hoppe, T., Matuschewski, K., Rape, M., Schlenker, S., Ulrich, H. D., and Jentsch, S. (2000) Activation of a membrane-bound transcription factor by regulated ubiquitin/proteasome-dependent processing. Cell. 102, 577-586

51. Sato, K., Ito, H., Yokoyama, A., Toba, G., and Yamamoto, D. (2019) Partial proteasomal degradation 
of Lola triggers the male-to-female switch of a dimorphic courtship circuit. Nat. Commun. $10.1038 / \mathrm{s} 41467-018-08146-1$

837 52. Bohère, J., Mancheno-Ferris, A., Al Hayek, S., Zanet, J., Valenti, P., Akino, K., Yamabe, Y., Inagaki, S., Chanut-Delalande, H., Plaza, S., Kageyama, Y., Osman, D., Polesello, C., and Payre, F. (2018) Shavenbaby and Yorkie mediate Hippo signaling to protect adult stem cells from apoptosis. Nat.

53. Lin, L., and Ghosh, S. (1996) A glycine-rich region in NF-kappaB p105 functions as a processing

54. Pan, Y., and Wang, B. (2007) A novel protein-processing domain in Gli2 and Gli3 differentially blocks

55. Wilson, M. D., Harreman, M., Taschner, M., Reid, J., Walker, J., Erdjument-Bromage, H., Tempst, P.,

56. Nassif, N. D., Cambray, S. E., and Kraut, D. A. (2014) Slipping up: Partial substrate degradation by and Svejstrup, J. Q. (2013) Proteasome-mediated processing of Def1, a critical step in the cellular response to transcription stress. Cell. 154, 983-995

57. Huang, X., Luan, B., Wu, J., and Shi, Y. (2016) An atomic structure of the human 26S proteasome.

59. Rape, M., Hoppe, T., Gorr, I., Kalocay, M., Richly, H., and Jentsch, S. (2001) Mobilization of

60. Wright, P. E., and Dyson, H. J. (2015) Intrinsically disordered proteins in cellular signalling and processed, membrane-tethered SPT23 transcription factor by CDC48UFD1/NPL4, a ubiquitin-selective chaperone. Cell. 107, 667-677

61. Polycarpou-Schwarz, M., Groß, M., Mestdagh, P., Schott, J., Grund, S. E., Hildenbrand, C., Rom, J., Diederichs, S. (2018) The cancer-associated microprotein CASIMO1 controls cell proliferation and interacts with squalene epoxidase modulating lipid droplet formation. Oncogene. 37, 4750-4768

62. Jun, S. Y., Brown, A. J., Chua, N. K., Yoon, J.-Y., Lee, J.-J., Yang, J. O. K., Jang, I., Jeon, S.-J., Choi, T.-I., Kim, C.-H., and Kim, N.-S. (2020) Reduction of squalene epoxidase by cholesterol accumulation accelerates colorectal cancer progression and metastasis. Gastroenterology doi: https://doi.org/10.1053/j.gastro.2020.09.009

63. Patel, P., and Woodgett, J. R. (2017) Glycogen synthase kinase 3: a kinase for all pathways? Curr. Top.

64. Valachovic, M., Garaiova, M., Holic, R., and Hapala, I. (2016) Squalene is lipotoxic to yeast cells defective in lipid droplet biogenesis. Biochem. Biophys. Res. Commun. 469, 1123-1128

65. Stopsack, K. H., Gerke, T. A., Andrén, O., Andersson, S. O., Giovannucci, E. L., Mucci, L. A., and Rider, J. R. (2017) Cholesterol uptake and regulation in high-grade and lethal prostate cancers. Carcinogenesis. 38, 806-811 


\section{Supplementary data}

\section{$877 \quad$ Supplementary figures}

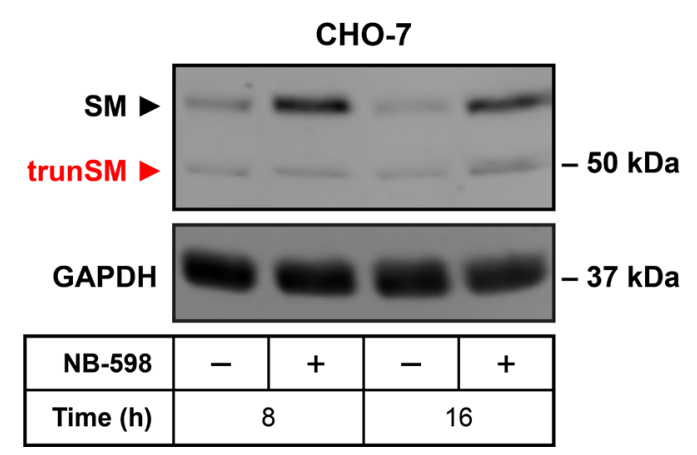

\section{Figure S1. Related to Fig. 1}

880 CHO-7 cells express a trunSM-like protein. CHO-7 cells were treated in the presence or absence

881 of $1 \mu \mathrm{M}$ NB-598 for the indicated times, and immunoblotting was performed for SM and 882 truncated SM (trunSM, red). Immunoblot is representative of $n=2$ independent experiments. 
A

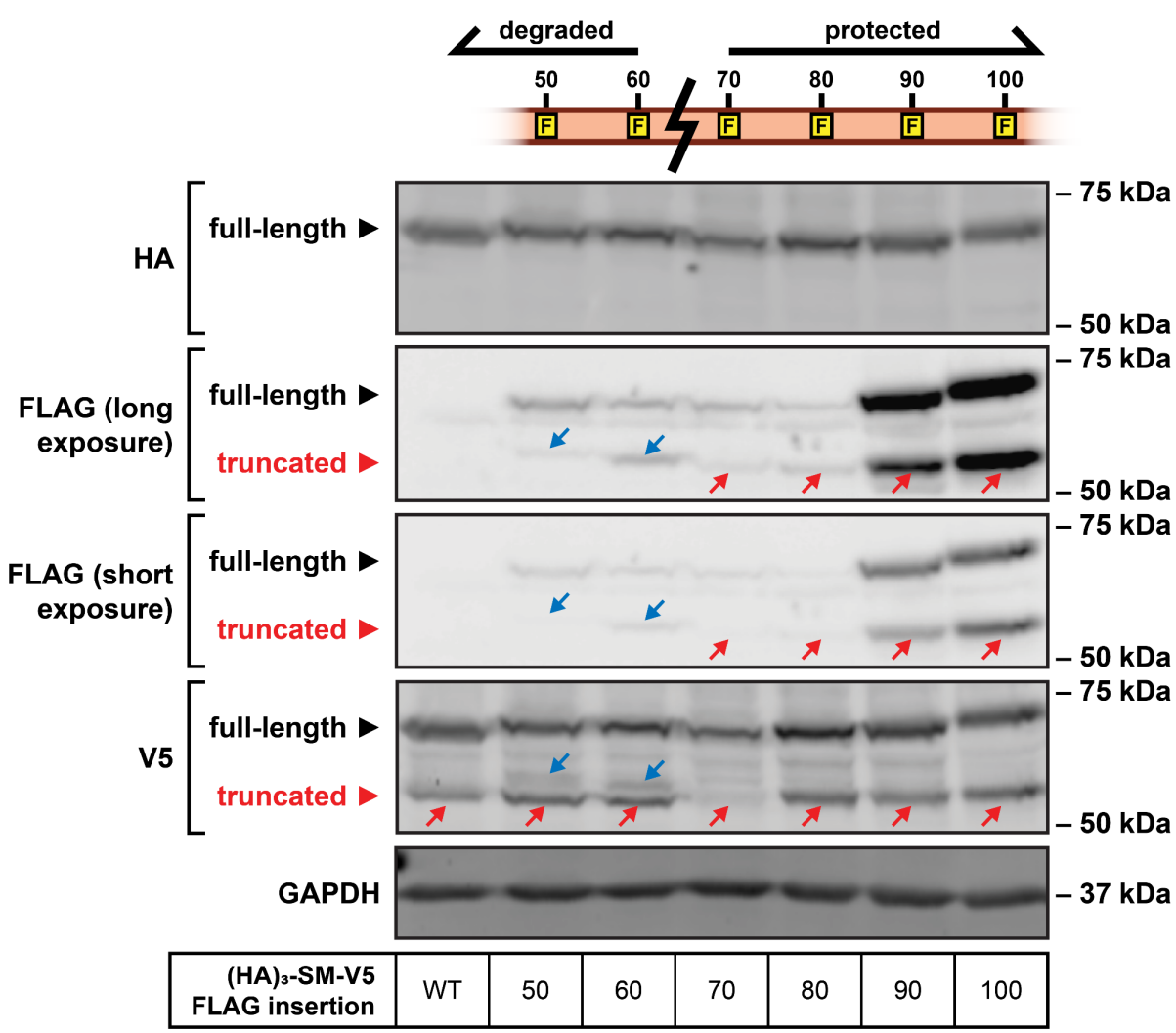

B
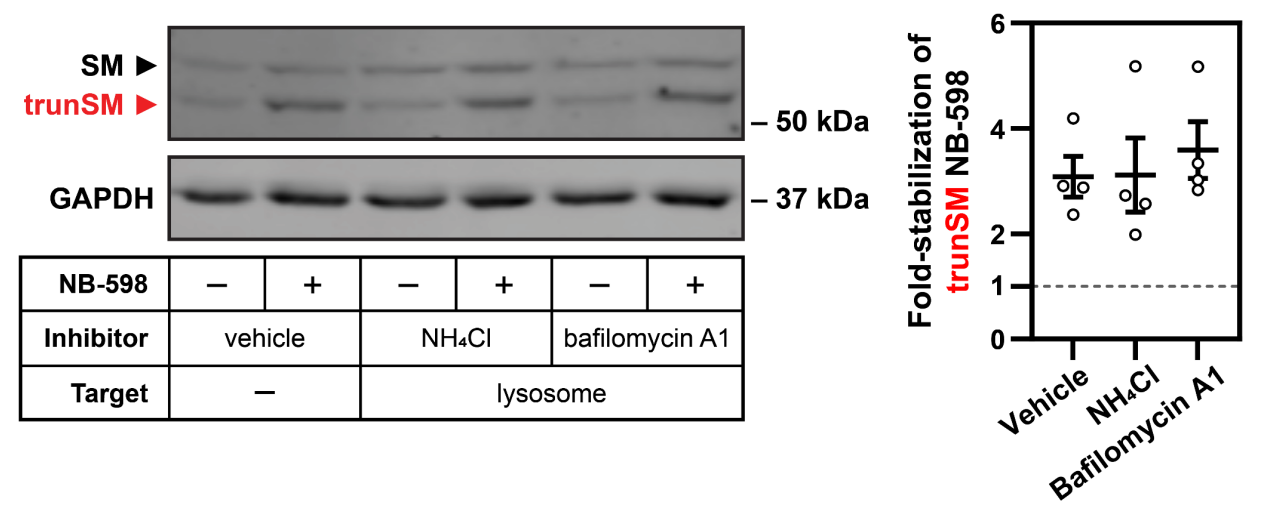

\section{K-cluster $\mathbf{1 + 2}$}

C

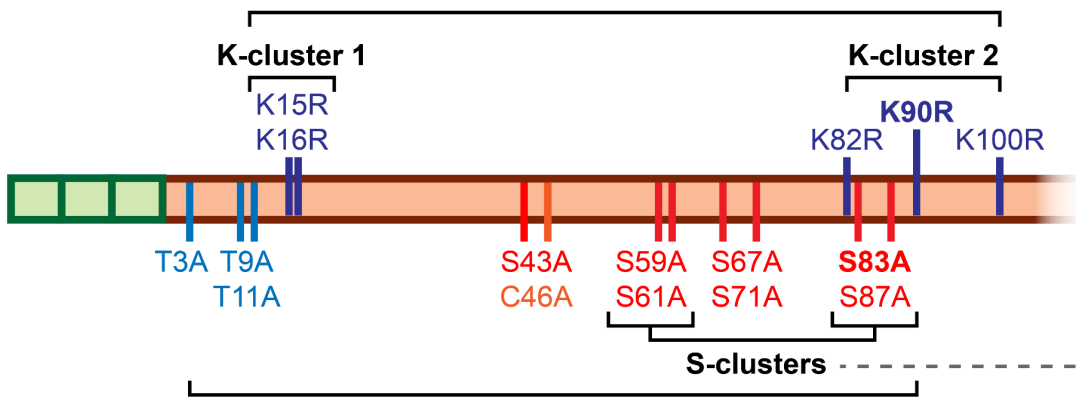

T/S/C-clusters
Effect on cholesterolaccelerated degradation

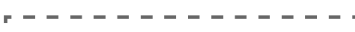

No effect

Regulate SM-N100

Regulate full-length SM 


\section{$884 \quad$ Figure S2. Related to Fig. 3}

885 (A) The estimated SM truncation site is between residues 60 and 70. HEK293T cells were 886 transfected with the indicated constructs for $24 \mathrm{~h}$, treated with $1 \mu \mathrm{M} \mathrm{NB}-598$ for $16 \mathrm{~h}$, and then 887 treated with $20 \mu \mathrm{M} \mathrm{MG132}$ for $8 \mathrm{~h}$. Immunoblot is representative of $n \geq 2$ independent 888 experiments. Red arrows indicate fragments corresponding to trunSM, and blue arrows indicate 889 additional FLAG-tagged fragments that do not correspond to trunSM.

890 (B) SM truncation does not depend on the lysosome. HEK293T cells were treated with $20 \mathrm{mM}$ 891 ammonium chloride $\left(\mathrm{NH}_{4} \mathrm{Cl}\right)$ or $10 \mathrm{nM}$ bafilomycin $\mathrm{A} 1$, in the presence or absence of $1 \mu \mathrm{M}$ 892 NB-598, for $8 \mathrm{~h}$. Graph depicts densitometric quantification of trunSM stabilization by NB-598. 893 Data presented as mean $\pm \operatorname{SEM}$ from $n=4$ independent experiments.

894 (C) Schematic of putative ubiquitination sites within the SM-N100 domain. Lysine residues are 895 not required for cholesterol-accelerated degradation of SM or SM-N100 [1, 2]. Serine residues 896 are required for maximal cholesterol-accelerated degradation of SM-N100 [1], while clusters of 897 threonine, cysteine and serine residues are required for maximal cholesterol-accelerated 898 degradation of full-length SM [1]. Bolded residues indicate known ubiquitination sites [1, 3]. 

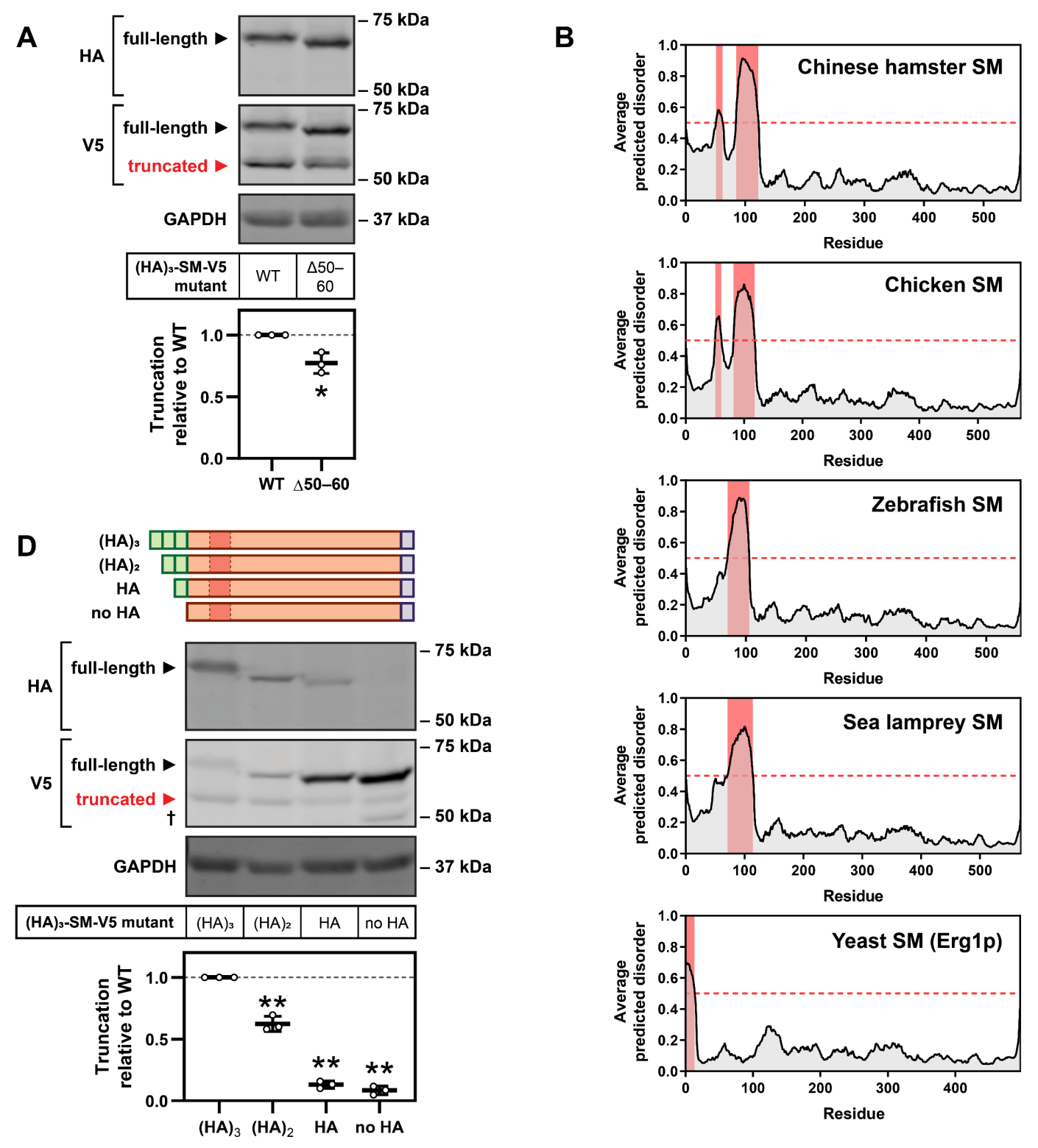

\footnotetext{
C Consensus 71 ISXILPXIIGFF $80^{-}$ Identity

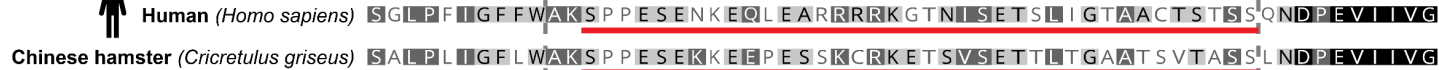
Chicken (Gallus gallus) ISALPL VGF FWAKPAAGSRRVEQPK SRIKGK I EVNVSIETHLTEAAS VTTLISPIQ YDPEVIVVG

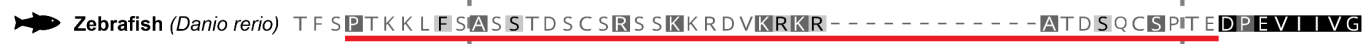
$\checkmark$ Sea lamprey (Petromyzon marinus) INGVY TINT L SITQE A E K HERL NMYR C G HQG GEP AVNG A GLRGP HAQ I G - - -I-DEE EVLIVG 


\section{Figure S3. Related to Fig. 4}

901 (A) A low-complexity sequence within the SM-N100 domain has a small effect on SM 902 truncation. HEK293T cells were transfected with the indicated constructs for $24 \mathrm{~h}$ and refreshed 903 in maintenance medium for $24 \mathrm{~h}$. Graph depicts densitometric quantification of truncation 904 normalized to the wild-type (WT) construct, which was set to 1 (dotted line). Data presented as 905 mean $\pm \operatorname{SEM}$ from $n=3$ independent experiments $(*, p \leq 0.05$, two-tailed paired t-test vs. WT).

906 (B) The intrinsic disorder of the SM 81-120 region is highly conserved amongst SM 907 orthologues. Intrinsically disordered regions (red) are indicated for SM orthologues from 908 Chinese hamster (Cricetulus griseus), chicken (Gallus gallus), zebrafish (Danio rerio), sea 909 lamprey (Petromyzon marinus) and yeast (Saccharomyces cerevisiae).

910 (C) The sequence of the SM 81-120 region is poorly conserved amongst SM orthologues. 911 Alignment of human SM residues 71-130 with SM orthologues from the indicated species. Red 912 bars indicate regions of intrinsic disorder, and grey dashed box indicates regions that were 913 substituted into SM constructs in Fig. 4C.

914 (D) Removal of HA tags from the SM N-terminus reduces truncation. HEK293T cells were 915 transfected with the indicated constructs for $24 \mathrm{~h}$ and refreshed in maintenance medium for $24 \mathrm{~h}$.

916 Graph depicts densitometric quantification of truncation normalized to the wild-type (WT) 917 construct, which was set to 1 (dotted line). Data presented as mean \pm SEM from $n=3$ 918 independent experiments $(* *, p \leq 0.01$, two-tailed paired t-test vs. WT). Dagger indicates a non919 trunSM fragment. 


\section{Supplementary tables}

\section{Table S1. siRNA and plasmids used for transfection}

\begin{tabular}{|c|c|}
\hline SiRNA & Description \\
\hline SIC001 & MISSION® universal negative control \#1 \\
\hline SASI_Hs01_00149248 & Targets human SQLE exon 9 (NM_003129) \\
\hline SASI_Hs01_00149256 & Targets human SQLE exon 1 (NM_003129) \\
\hline SASI_Hs01_00095058 & Targets human UBE2J2 (NM_058167) \\
\hline SASI_Hs01_00105239 & Targets human MARCHF6 (NM_005885) \\
\hline SASI_Hs01_00118726 & Targets human $V C P$ (NM_007126) \\
\hline Plasmid & Description \\
\hline $\begin{array}{l}\text { totalSQLE qRT-PCR } \\
\text { standard }\end{array}$ & $\begin{array}{l}\text { pGL3-Basic vector containing a totalSQLE (NM_003129.4, exon 7) qRT- } \\
\text { PCR amplicon sequence. }\end{array}$ \\
\hline $\begin{array}{l}\text { fullSQLE qRT-PCR } \\
\text { standard }\end{array}$ & $\begin{array}{l}\text { pGL3-Basic vector containing a fullSQLE (NM_003129.4, exon 1) qRT- } \\
\text { PCR amplicon sequence. }\end{array}$ \\
\hline $\begin{array}{l}\text { trunSQLE1 qRT-PCR } \\
\text { standard }\end{array}$ & $\begin{array}{l}\text { pGL3-Basic vector containing a trunSQLE1 (ENST00000523430.5, exon 1) } \\
\text { qRT-PCR amplicon sequence. }\end{array}$ \\
\hline $\begin{array}{l}\text { trunSQLE2 qRT-PCR } \\
\text { standard }\end{array}$ & $\begin{array}{l}\text { pGL3-Basic vector containing a trunSQLE2 (XM_011517246.2, exon 1) } \\
\text { qRT-PCR amplicon sequence. }\end{array}$ \\
\hline pCMV-(HA) $)_{3}-\mathrm{SM}-\mathrm{V} 5$ & $\begin{array}{l}\text { pcDNA3.1/V5-His TOPO vector containing the coding sequence of human } \\
\text { SM (NM_003129.4) fused with three N-terminal HA epitope tags and C- } \\
\text { terminal V5 and } 6 \times \text { His epitope tags, under the transcriptional control of a } \\
\text { constitutive CMV promoter. Generated previously in our laboratory by Dr } \\
\text { Julian Stevenson. }\end{array}$ \\
\hline $\begin{array}{l}\mathrm{pCMV}-(\mathrm{HA})_{3}-\mathrm{SM}-\mathrm{V} 5 \\
\mathrm{~K} 15 \mathrm{R}\end{array}$ & pCMV-(HA) $)_{3}-\mathrm{SM}-\mathrm{V} 5$ containing an SM K15R substitution. \\
\hline $\begin{array}{l}\text { pCMV-(HA) }{ }_{3}-\mathrm{SM}-\mathrm{V} 5 \\
\mathrm{~K} 16 \mathrm{R}\end{array}$ & pCMV-(HA) $)_{3}-\mathrm{SM}-\mathrm{V} 5$ containing an SM K16R substitution. \\
\hline $\begin{array}{l}\text { pCMV-(HA) })_{3}-\mathrm{SM}-\mathrm{V} 5 \\
\mathrm{~K} 82 \mathrm{R}\end{array}$ & pCMV-(HA) $)_{3}-\mathrm{SM}-\mathrm{V} 5$ containing an SM K82R substitution. \\
\hline $\begin{array}{l}\text { pCMV-(HA) })_{3}-\mathrm{SM}-\mathrm{V} 5 \\
\text { K90R }\end{array}$ & pCMV-(HA) $)_{3}-\mathrm{SM}-\mathrm{V} 5$ containing an SM K90R substitution. \\
\hline $\begin{array}{l}\text { pCMV-(HA) })_{3}-\mathrm{SM}-\mathrm{V} 5 \\
\mathrm{~K} 100 \mathrm{R}\end{array}$ & pCMV-(HA) $)_{3}-\mathrm{SM}-\mathrm{V} 5$ containing an SM K100R substitution. \\
\hline $\begin{array}{l}\text { pCMV-(HA) }{ }_{3}-\mathrm{SM}-\mathrm{V} 5 \\
\text { K-cluster } 1\end{array}$ & pCMV-(HA) $)_{3}-\mathrm{SM}-\mathrm{V} 5$ containing SM K15R and K16R substitutions. \\
\hline $\begin{array}{l}\text { pCMV-(HA) })_{3}-\mathrm{SM}-\mathrm{V} 5 \\
\mathrm{~K} \text {-cluster } 2\end{array}$ & $\begin{array}{l}\text { pCMV-(HA) } 3-S M-V 5 \text { containing SM K82R, K90R and K100R } \\
\text { substitutions. }\end{array}$ \\
\hline
\end{tabular}




\begin{tabular}{|c|c|}
\hline $\begin{array}{l}\text { pCMV-(HA) })_{3}-\mathrm{SM}-\mathrm{V} 5 \\
\text { K-cluster } 1 / 2\end{array}$ & $\begin{array}{l}\text { pCMV-(HA) }{ }_{3}-\mathrm{SM}-\mathrm{V} 5 \text { containing SM K15R, K16R, K82R, K90R and } \\
\text { K100R substitutions. }\end{array}$ \\
\hline $\begin{array}{l}\text { pCMV-(HA) }{ }_{3}-\mathrm{SM}-\mathrm{V} 5 \\
\text { S-clusters }\end{array}$ & $\begin{array}{l}\text { pCMV-(HA) } 3 \text {-SM-V5 containing SM S59A, S61A, S83A and S97A } \\
\text { substitutions. }\end{array}$ \\
\hline $\begin{array}{l}\text { pCMV-(HA) })_{3}-\mathrm{SM}-\mathrm{V} 5 \\
\text { T/S/C-clusters }\end{array}$ & $\begin{array}{l}\text { pCMV-(HA) }{ }_{3}-\mathrm{SM}-\mathrm{V} 5 \text { containing SM T3A, T9A, T11A, S43A, C46A, } \\
\text { S59A, S61A, S67A, S71A, S83A and S87A substitutions. }\end{array}$ \\
\hline $\begin{array}{l}\mathrm{pCMV}-(\mathrm{HA})_{3}-\mathrm{SM}-\mathrm{V} 5 \\
\Delta 81-120\end{array}$ & pCMV-(HA) 3 -SM-V5 containing a deletion of SM residues 81-120. \\
\hline $\begin{array}{l}\mathrm{pCMV}-(\mathrm{HA})_{3}-\mathrm{SM}-\mathrm{V} 5 \\
\Delta 91-110\end{array}$ & pCMV-(HA) $)_{3}-\mathrm{SM}-\mathrm{V} 5$ containing a deletion of SM residues $91-110$. \\
\hline $\begin{array}{l}\text { pCMV-(HA) })_{3}-\mathrm{SM}-\mathrm{V} 5 \\
\text { dup } 81-120\end{array}$ & $\begin{array}{l}\text { pCMV-(HA) }{ }_{3}-\mathrm{SM}-\mathrm{V} 5 \text { containing a tandem duplication of SM residues } 81- \\
120 .\end{array}$ \\
\hline $\begin{array}{l}\text { pCMV-(HA) })_{3}-\mathrm{SM}-\mathrm{V} 5 \\
\text { (Chinese hamster) }\end{array}$ & $\begin{array}{l}\text { pCMV-(HA) }{ }_{3}-\mathrm{SM}-\mathrm{V} 5 \text { containing a substitution of SM residues } 81-120 \text { with } \\
\text { Cricetulus griseus } \mathrm{SM} \text { residues } 83-122 \text {. }\end{array}$ \\
\hline $\begin{array}{l}\text { pCMV-(HA) })_{3}-\mathrm{SM}-\mathrm{V} 5 \\
\text { (chicken) }\end{array}$ & $\begin{array}{l}\text { pCMV-(HA) }{ }_{3}-\mathrm{SM}-\mathrm{V} 5 \text { containing a substitution of SM residues } 81-120 \text { with } \\
\text { Gallus gallus } \text { SM residues } 80-119 \text {. }\end{array}$ \\
\hline $\begin{array}{l}\text { pCMV-(HA) })_{3}-\mathrm{SM}-\mathrm{V} 5 \\
\text { (zebrafish) }\end{array}$ & $\begin{array}{l}\text { pCMV-(HA) }{ }_{3}-\mathrm{SM}-\mathrm{V} 5 \text { containing a substitution of SM residues } 81-120 \text { with } \\
\text { Danio rerio } \mathrm{SM} \text { residues } 77-104 \text {. }\end{array}$ \\
\hline $\begin{array}{l}\text { pCMV-(HA) })_{3}-\mathrm{SM}-\mathrm{V} 5 \\
\text { (sea lamprey) }\end{array}$ & $\begin{array}{l}\text { pCMV-(HA) }{ }_{3}-\mathrm{SM}-\mathrm{V} 5 \text { containing a substitution of SM residues } 81-120 \text { with } \\
\text { Petromyzon marinus SM residues } 80-116 \text {. }\end{array}$ \\
\hline $\begin{array}{l}\text { pCMV-(HA) }{ }_{3}-\mathrm{GAr}-\mathrm{SM}- \\
\text { V5 }\end{array}$ & $\begin{array}{l}\text { pCMV-(HA) }{ }_{3} \text {-SM-V5 containing an insertion of a glycine-alanine repeat } \\
\text { sequence (AGAGGGAGAGGAGGAGGAGAGGAGAGGGAG) from the } \\
\text { Epstein-Barr virus nuclear antigen-1. }\end{array}$ \\
\hline $\begin{array}{l}\text { pCMV-(HA) })_{3}-(\mathrm{GAr})_{2}- \\
\text { SM-V5 }\end{array}$ & $\begin{array}{l}\mathrm{pCMV}-(\mathrm{HA})_{3}-\mathrm{SM}-\mathrm{V} 5 \text { containing an insertion of two glycine-alanine repeat } \\
\text { sequences from the Epstein-Barr virus nuclear antigen-1. }\end{array}$ \\
\hline $\begin{array}{l}\text { pCMV-(HA) }{ }_{3} \text {-DHFR- } \\
\text { SM-V5 }\end{array}$ & $\begin{array}{l}\text { pCMV-(HA) })_{3}-\mathrm{SM}-\mathrm{V} 5 \text { containing an insertion of the coding sequence of } \\
\text { human dihydrofolate reductase (DHFR, NM_000791.4). }\end{array}$ \\
\hline $\begin{array}{l}\text { pCMV-(HA) })_{3}-\mathrm{SM}-\mathrm{V} 5 \\
\mathrm{Q} 168 \mathrm{~A}\end{array}$ & pCMV-(HA) ${ }_{3}-\mathrm{SM}-\mathrm{V} 5$ containing an SM Q168A substitution. \\
\hline $\begin{array}{l}\text { pCMV-(HA) } 3-\mathrm{SM}-\mathrm{V} 5 \\
\mathrm{Y} 195 \mathrm{~A}\end{array}$ & pCMV-(HA) $)_{3}-\mathrm{SM}-\mathrm{V} 5$ containing an SM Y195A substitution. \\
\hline $\begin{array}{l}\text { pCMV-(HA) })_{3}-\mathrm{SM}-\mathrm{V} 5 \\
\mathrm{Y} 195 \mathrm{~F}\end{array}$ & pCMV-(HA) $)_{3}-\mathrm{SM}-\mathrm{V} 5$ containing an SM Y195F substitution. \\
\hline $\begin{array}{l}\text { pCMV-(HA) })_{3}-\mathrm{SM}-\mathrm{V} 5 \\
\text { Q207A }\end{array}$ & pCMV-(HA) $)_{3}-\mathrm{SM}-\mathrm{V} 5$ containing an SM Q207A substitution. \\
\hline $\begin{array}{l}\text { pCMV-(HA) })_{3}-\mathrm{SM}-\mathrm{V} 5 \\
\text { F224A }\end{array}$ & pCMV-(HA) $)_{3}-\mathrm{SM}-\mathrm{V} 5$ containing an SM F224A substitution. \\
\hline $\begin{array}{l}\text { pCMV-(HA) })_{3}-\mathrm{SM}-\mathrm{V} 5 \\
\mathrm{D} 272 \mathrm{~A}\end{array}$ & pCMV-(HA) $)_{3}-\mathrm{SM}-\mathrm{V} 5$ containing an SM D272A substitution. \\
\hline
\end{tabular}




\begin{tabular}{|c|c|}
\hline $\begin{array}{l}\text { pCMV-(HA) })_{3}-\mathrm{SM}-\mathrm{V} 5 \\
\mathrm{Y} 335 \mathrm{~F}\end{array}$ & pCMV-(HA) 3 -SM-V5 containing an SM Y335F substitution. \\
\hline $\begin{array}{l}\text { pCMV-(HA) })_{3}-\mathrm{SM}-\mathrm{V} 5 \\
\text { Y365A }\end{array}$ & pCMV-(HA) $)_{3}-\mathrm{SM}-\mathrm{V} 5$ containing an SM Y365A substitution. \\
\hline $\begin{array}{l}\text { pCMV-(HA) })_{3}-\mathrm{SM}-\mathrm{V} 5 \\
\text { T417S }\end{array}$ & pCMV-(HA) $)_{3}-\mathrm{SM}-\mathrm{V} 5$ containing an SM T417S substitution. \\
\hline pTK-SM-N100-GFP-V5 & $\begin{array}{l}\text { pcDNA3.1/V5-His TOPO vector containing the coding sequence of human } \\
\text { SM-N100 (NM_003129.4) fused with green fluorescent protein (GFP) and } \\
\text { C-terminal V5 and } 6 \times \text { His epitope tags, under the transcriptional control of a } \\
\text { constitutive TK promoter. Generated previously by our laboratory [2]. }\end{array}$ \\
\hline $\begin{array}{l}\text { pCMV-(HA) })_{3}-\mathrm{SM}-\mathrm{V} 5 \\
\text { FLAG50 }\end{array}$ & $\begin{array}{l}\text { pCMV-(HA) })_{3}-\mathrm{SM}-\mathrm{V} 5 \text { containing a FLAG epitope tag insertion after SM } \\
\text { residue } 50 .\end{array}$ \\
\hline $\begin{array}{l}\text { pCMV-(HA) })_{3}-\mathrm{SM}-\mathrm{V} 5 \\
\text { FLAG60 }\end{array}$ & $\begin{array}{l}\text { pCMV-(HA) })_{3}-\mathrm{SM}-\mathrm{V} 5 \text { containing a FLAG epitope tag insertion after SM } \\
\text { residue } 60 .\end{array}$ \\
\hline $\begin{array}{l}\text { pCMV-(HA) }{ }_{3}-\mathrm{SM}-\mathrm{V} 5 \\
\text { FLAG70 }\end{array}$ & $\begin{array}{l}\text { pCMV-(HA) } 3 \text {-SM-V5 containing a FLAG epitope tag insertion after SM } \\
\text { residue } 70 .\end{array}$ \\
\hline $\begin{array}{l}\text { pCMV-(HA) }{ }_{3}-\mathrm{SM}-\mathrm{V} 5 \\
\text { FLAG80 }\end{array}$ & $\begin{array}{l}\text { pCMV-(HA) } 3 \text {-SM-V5 containing a FLAG epitope tag insertion after SM } \\
\text { residue } 80 .\end{array}$ \\
\hline $\begin{array}{l}\text { pCMV-(HA) }{ }_{3}-\mathrm{SM}-\mathrm{V} 5 \\
\text { FLAG90 }\end{array}$ & $\begin{array}{l}\text { pCMV-(HA) } 3 \text {-SM-V5 containing a FLAG epitope tag insertion after SM } \\
\text { residue } 90 .\end{array}$ \\
\hline $\begin{array}{l}\text { pCMV-(HA) })_{3}-\mathrm{SM}-\mathrm{V} 5 \\
\text { FLAG100 }\end{array}$ & $\begin{array}{l}\text { pCMV-(HA) })_{3}-\mathrm{SM}-\mathrm{V} 5 \text { containing a FLAG epitope tag insertion after SM } \\
\text { residue } 100 .\end{array}$ \\
\hline $\begin{array}{l}\mathrm{pCMV}-(\mathrm{HA})_{3}-\mathrm{SM}-\mathrm{V} 5 \\
\Delta 50-60\end{array}$ & pCMV-(HA) $)_{3}-\mathrm{SM}-\mathrm{V} 5$ containing a deletion of SM residues $50-60$. \\
\hline $\mathrm{pCMV}-(\mathrm{HA})_{2}-\mathrm{SM}-\mathrm{V} 5$ & pCMV-(HA) $)_{3}-\mathrm{SM}-\mathrm{V} 5$ containing a deletion of one HA epitope tag. \\
\hline pCMV-HA-SM-V5 & pCMV-(HA) $)_{3}-\mathrm{SM}-\mathrm{V} 5$ containing a deletion of two HA epitope tags. \\
\hline pCMV-SM-V5 & $\begin{array}{l}\text { pcDNA3.1/V5-His TOPO vector containing the coding sequence of human } \\
\text { SM (NM_003129.4) fused with C-terminal V5 and } 6 \times \text { His epitope tags, } \\
\text { under the transcriptional control of a constitutive CMV promoter. Generated } \\
\text { previously in our laboratory [2]. }\end{array}$ \\
\hline
\end{tabular}




\section{Table S2. Primers used for qRT-PCR and DNA cloning}

924 Non-annealing nucleotides for DNA insertions, deletions and substitutions are indicated in 925 lowercase. Abbreviations for cloning methods: OEC (overlap extension cloning) [4] PIPE 926 (polymerase incomplete primer extension cloning) [5]; SLIC (sequence- and ligation927 independent cloning) [6].

\begin{tabular}{|c|c|c|c|}
\hline \multicolumn{2}{|c|}{ qRT-PCR primer pair } & \multirow{2}{*}{$\begin{array}{l}\text { Primer sequence }\left(\mathbf{5}^{\prime}-\mathbf{3}^{\prime}\right) \\
\text { AGGTTGCCATCCTCAGTCGTC } \\
\text { TTGCCACCACACTGTCCGTC } \\
\end{array}$} & \multirow{2}{*}{$\begin{array}{l}\text { Reference } \\
\text { This study }\end{array}$} \\
\hline$P B G D$ & $\begin{array}{l}\text { Forward } \\
\text { Reverse }\end{array}$ & & \\
\hline totalSQLE & $\begin{array}{l}\text { Forward } \\
\text { Reverse }\end{array}$ & $\begin{array}{l}\text { GCTTCCTTCCTCCTTCATCAGTG } \\
\text { GCAACAGTCATTCCTCCACCA }\end{array}$ & This study \\
\hline fullSQLE & $\begin{array}{l}\text { Forward } \\
\text { Reverse }\end{array}$ & $\begin{array}{l}\text { CCAGTTCGCCCTCTTCTCGG } \\
\text { ATTGGTTCCTTTTCTGCGCCTC }\end{array}$ & This study \\
\hline trunSQLE1 & $\begin{array}{l}\text { Forward } \\
\text { Reverse }\end{array}$ & $\begin{array}{l}\text { CCCGCGAGGGATGCTGCG } \\
\text { CTTCTGGGTCATTCTGAGAAGATG }\end{array}$ & This study \\
\hline $\operatorname{trunSQLE2}$ & $\begin{array}{l}\text { Forward } \\
\text { Reverse }\end{array}$ & $\begin{array}{l}\text { GGGTAAGGATTGGATTTGTGCC } \\
\text { TGGGTCATTCTGAGAAGATGTTGA }\end{array}$ & This study \\
\hline \multicolumn{2}{|c|}{ DNA cloning primer pair } & Primer sequence $\left(5^{\prime}-3^{\prime}\right)$ & Method \\
\hline $\begin{array}{l}\text { totalSQLE } \\
\text { qRT-PCR } \\
\text { standard }\end{array}$ & $\begin{array}{l}\text { Forward } \\
\text { Reverse }\end{array}$ & $\begin{array}{l}\text { cattccggtactgttggtaaagccaccGCTTCCTTCCTCCTTCATCA } \\
\text { GTG } \\
\text { ggccggccgeccegactctagaaGCAACAGTCATTCCTCCACCA }\end{array}$ & \multirow{4}{*}{$\begin{array}{l}\text { OEC (amplified } \\
\text { from HEK293T } \\
\text { cDNA and used } \\
\text { to extend the } \\
\text { pGL3-Basic } \\
\text { plasmid) }\end{array}$} \\
\hline $\begin{array}{l}\text { fullSQLE } \\
\text { qRT-PCR } \\
\text { standard }\end{array}$ & $\begin{array}{l}\text { Forward } \\
\text { Reverse }\end{array}$ & $\begin{array}{l}\text { cattccggtactgttggtaaagccaccCCAGTTCGCCCTCTTCTCGG } \\
\text { ggceggecgeccegactctagaaATTGGTTCCTTTTCTGCGCCTC }\end{array}$ & \\
\hline $\begin{array}{l}\text { trunSQLE1 } \\
\text { qRT-PCR } \\
\text { standard }\end{array}$ & $\begin{array}{l}\text { Forward } \\
\text { Reverse }\end{array}$ & $\begin{array}{l}\text { cattccggtactgttggtaaagccaccCCCGCGAGGGATGCTGCG } \\
\text { ggccggccgeccegactctagaaCTTCTGGGTCATTCTGAGAAG } \\
\text { ATG }\end{array}$ & \\
\hline $\begin{array}{l}\text { trunSQLE2 } \\
\text { qRT-PCR } \\
\text { standard }\end{array}$ & Forward & $\begin{array}{l}\text { cattccggtactgttggtaaagccaccGGGTAAGGATTGGATTTGTG } \\
\text { CC } \\
\text { ggccggccgccccgactctagaaTGGGTCATTCTGAGAAGATGT } \\
\text { TGA }\end{array}$ & \\
\hline BGHR2 & Reverse & GCGATGCAATTTCCTCATTT & $\begin{array}{l}\text { OEC (generic } \\
\text { reverse primer } \\
\text { for point } \\
\text { mutations) }\end{array}$ \\
\hline $\mathrm{K} 15 \mathrm{R}$ & Forward & $\begin{array}{l}\text { GCCACTTTCACCTATTTTTATAgGAAGTTCGGGGACT } \\
\text { TCATCAC }\end{array}$ & \multirow{7}{*}{$\begin{array}{l}\text { OEC (with } \\
\text { BGHR2 reverse) }\end{array}$} \\
\hline K16R & Forward & $\begin{array}{l}\text { GCCACTTTCACCTATTTTTATAAGAgGTTCGGGGACT } \\
\text { TCATCAC }\end{array}$ & \\
\hline $\mathrm{K} 82 \mathrm{R}$ & Forward & GGCTTCTTCTGGGCCAggTCCCCCCCTGAATCAG & \\
\hline K90R & Forward & CAGAAAATAgGGAGCAGCTC & \\
\hline K100R & Forward & $\begin{array}{l}\text { CCAGGAGGCGCAGAAggGGAACCAATATTTCAGAAA } \\
\text { CAAG }\end{array}$ & \\
\hline $\mathrm{K} 15 \mathrm{R} / \mathrm{K} 16 \mathrm{R}$ & & & \\
\hline $\begin{array}{l}\text { K82R / K90R } \\
\text { / K100R }\end{array}$ & Forward & Appropriate mutagenic primer/s & \\
\hline
\end{tabular}




\begin{tabular}{|c|c|c|c|}
\hline $\begin{array}{l}\text { K15R / K16R } \\
\text { / K82R / } \\
\text { K90R / K100R }\end{array}$ & Forward & Appropriate mutagenic primer/s & $\begin{array}{l}\text { OEC (with } \\
\text { BGHR2 reverse) }\end{array}$ \\
\hline $\mathrm{T} / \mathrm{S} / \mathrm{C}$-clusters & $\begin{array}{l}\text { Vector: } \\
\text { Forward } \\
\text { Reverse } \\
\text { Insert: } \\
\text { Forward } \\
\text { Reverse }\end{array}$ & $\begin{array}{l}\text { GGAACCAATATTTCAGAAACAAGCTTAATAG } \\
\text { AGCGTAATCTGGAACGTCATATG } \\
\text { gttccagattacgctTGGACTTTTCTGGGCATTGCC } \\
\text { TGAAATATTGGTTCCTTTTCTGCGC }\end{array}$ & $\begin{array}{l}\text { PIPE } \\
\text { (insert amplified } \\
\text { from SM-N100 } \\
\text { plasmids } \\
\text { generated in [1]) }\end{array}$ \\
\hline$\Delta 81-120$ & $\begin{array}{l}\text { Forward } \\
\text { Reverse }\end{array}$ & $\begin{array}{l}\text { attggcttcttctggCAGAATGACCCAGAAGTTATCATCG } \\
\text { ttctgggtcattctgCCAGAAGAAGCCAATGAAAGGCAG }\end{array}$ & PIPE \\
\hline$\Delta 91-110$ & $\begin{array}{l}\text { Forward } \\
\text { Reverse }\end{array}$ & $\begin{array}{l}\text { gaatcagaaaataagGGAACAGCTGCCTGTACATCAAC } \\
\text { acaggcagctgttcCCTTATTTTCTGATTCAGGGGGG }\end{array}$ & PIPE \\
\hline dup81-120 & $\begin{array}{l}\text { Vector: } \\
\text { Forward } \\
\text { Reverse } \\
\text { Insert: } \\
\text { Forward } \\
\text { Reverse }\end{array}$ & $\begin{array}{l}\text { AAATCCCCCCCTGAATCAGAAAATAAGGAG } \\
\text { GGCCCAGAAGAAGCCAATGAAAGG } \\
\text { ggcttcttctgggccAAATCCC } \\
\text { ttcagggggggatttCTGAGAAGATGTTGATGTACAGGCAGC }\end{array}$ & $\begin{array}{l}\text { SLIC } \\
\text { (insert amplified } \\
\text { from pCMV- } \\
\text { HA }_{3}-\mathrm{SM}-\mathrm{V} 5 \text { ) }\end{array}$ \\
\hline $\begin{array}{l}81-120 \\
\text { (Chinese } \\
\text { hamster) }\end{array}$ & $\begin{array}{l}\text { Forward } \\
\text { Reverse }\end{array}$ & $\begin{array}{l}\text { cetgcctttcattggettcttctggGCCAAGTCACCCCCTGAG } \\
\text { cacgatgataacttctgggtcattctgAGAAGATGCTGTTACTGAGG } \\
\text { TAGC }\end{array}$ & \\
\hline $\begin{array}{l}81-120 \\
\text { (chicken) }\end{array}$ & $\begin{array}{l}\text { Forward } \\
\text { Reverse }\end{array}$ & $\begin{array}{l}\text { cctgcetttcattggettcttctggGCCAAGCCCGCCGC } \\
\text { cacgatgataacttctgggtcattctgcggagacaatgtcgttacagaagccgcctcag } \\
\text { tgaggtgggtttcggacacgttcacCTCGATCTTGCCCTTCCTG } \\
\text { C }\end{array}$ & $\begin{array}{l}\text { OEC (amplified } \\
\text { from SM-N100- } \\
\text { GFP-V5 } \\
\text { plasmids }\end{array}$ \\
\hline $\begin{array}{l}81-120 \\
\text { (zebrafish) }\end{array}$ & $\begin{array}{l}\text { Forward } \\
\text { Reverse }\end{array}$ & $\begin{array}{l}\text { cetgectttcattggettcttctggGCCTCTAGCACCGATAGCTG } \\
\text { cacgatgataacttctgggtcattctgtgggetacattgGGAATCTGTGGCT } \\
\text { CTCTTCCG }\end{array}$ & $\begin{array}{l}\text { and used to } \\
\text { extend the } \\
\text { pCMV-HA3- }\end{array}$ \\
\hline $\begin{array}{l}81-120(\text { sea } \\
\text { lamprey) }\end{array}$ & $\begin{array}{l}\text { Forward } \\
\text { Reverse }\end{array}$ & $\begin{array}{l}\text { cctgectttcattggettcttctggACCCAGGAAGCAGAAAAACAC } \\
\text { G } \\
\text { cacgatgataacttctgggtcattctgaccaatttgggcgtgaggcceccggaggecc } \\
\text { gcaccattgacggecggCTCTCCCCCCTGGTGC }\end{array}$ & SM-V5 plasmid) \\
\hline $\begin{array}{l}\text { pCMV-(HA) })_{3-} \\
(\text { GAr })_{2}-\mathrm{SM}- \\
\text { V5 }\end{array}$ & $\begin{array}{l}\text { Vector: } \\
\text { Forward } \\
\text { Reverse } \\
\text { GAr } \\
\text { generation: } \\
\text { Forward } \\
\text { Reverse } \\
\text { Insert: } \\
\text { Forward } \\
\text { Reverse }\end{array}$ & $\begin{array}{l}\text { GCTGGAGCAGGCGGTGGAGCAGGTGCTGGAGGTGC } \\
\text { AGGTGGAGCAGGCGGTGCAGGAGCA } \\
\text { ACCTGCTCCACCTCCAGCACCTGCACCACCTGCTCC } \\
\text { TGCACCGCCTGCTCCACCTGCACC } \\
\text { tccatatgacgttccagattacgctGCTGGAGCAGGCGGTGGAGC } \\
\text { gaaagtggcaatgcceagaaagtccaACCTGCTCCACCTCCAGCA } \\
\text { C }\end{array}$ & $\begin{array}{l}\text { SLIC } \\
\text { ('GAr } \\
\text { generation' } \\
\text { primers extended } \\
\text { and used as } \\
\text { template for } \\
\text { insert } \\
\text { amplification) }\end{array}$ \\
\hline
\end{tabular}




\begin{tabular}{|c|c|c|c|}
\hline $\begin{array}{l}\text { pCMV-(HA) }{ }_{3-}^{-} \\
\text {DHFR-SM-V5 }\end{array}$ & $\begin{array}{l}\text { Vector: } \\
\text { Forward } \\
\text { Reverse } \\
\text { Insert: } \\
\text { Forward } \\
\text { Reverse }\end{array}$ & $\begin{array}{l}\text { TGGACTTTTCTGGGCATTGCC } \\
\text { AGCGTAATCTGGAACGTCATATG } \\
\text { gttccagattacgctGTTGGTTCGCTAAACTGCATCG } \\
\text { gcccagaaaagtccAATCATTCTTCTCATATACTTCAAATTT } \\
\text { GTAC }\end{array}$ & $\begin{array}{l}\text { PIPE (insert } \\
\text { amplified from } \\
\text { HEK293T } \\
\text { cDNA) }\end{array}$ \\
\hline Q168A & Forward & GTTGGAGAATTCCTGgccCCGGGTGGTTATC & \multirow{9}{*}{$\begin{array}{l}\text { OEC (with } \\
\text { BGHR2 reverse) }\end{array}$} \\
\hline Y195A & Forward & CCAGGTTGTAAATGGTgcCATGATTCATGATCAGG & \\
\hline Y195F & Forward & CCAGGTTGTAAATGGTTtCATGATTCATGATCAGG & \\
\hline Q207A & Forward & AAAGCAAATCAGAGGTTgccATTCCTTACCCTCTGTC & \\
\hline F224A & Forward & CAGAGTGGAAGAGCTgcCCATCACGGAAGATTC & \\
\hline D272A & Forward & $\begin{array}{l}\text { AGGATAAAGAGACTGGAGccATCAAGGAACTCCATG } \\
\text { C }\end{array}$ & \\
\hline Y335F & Forward & GTCCAGTTCTCATCTtCCAGATTTCATCCAG & \\
\hline Y365A & Forward & $\begin{array}{l}\text { GAATACATGGTTGAAAAAATTgcCCCACAAATACCT } \\
\text { GATC }\end{array}$ & \\
\hline $\mathrm{T} 417 \mathrm{~S}$ & Forward & $\begin{array}{l}\text { AATATGAGGCATCCACTTtCTGGTGGAGGAATGACT } \\
\text { G }\end{array}$ & \\
\hline $\begin{array}{l}\text { FLAG50 } \\
\text { insertion }\end{array}$ & $\begin{array}{l}\text { Forward } \\
\text { Reverse }\end{array}$ & $\begin{array}{l}\text { gactacaaagacgatgacgacaagGGGGGTCTCCTCGGGC } \\
\text { cttgtcgtcatcgtctttgtagtcGTTTCGGTGGCGACAGC }\end{array}$ & PIPE \\
\hline $\begin{array}{l}\text { FLAG60 } \\
\text { insertion }\end{array}$ & $\begin{array}{l}\text { Forward } \\
\text { Reverse }\end{array}$ & $\begin{array}{l}\text { gactacaaagacgatgacgacaagTCCCAGTTCGCCCTCTTCTCG } \\
\text { cttgtcgtcatcgtctttgtagtcGCCGCTCTGCTGGCGCC }\end{array}$ & PIPE \\
\hline $\begin{array}{l}\text { FLAG70 } \\
\text { insertion }\end{array}$ & $\begin{array}{l}\text { Forward } \\
\text { Reverse }\end{array}$ & $\begin{array}{l}\text { gactacaaagacgatgacgacaagTCAGGCCTGCCTTTCATTGGC } \\
\text { cttgtcgtcatcgtctttgtagtcGAGAATATCCGAGAAGAGGGCG } \\
\text { AAC }\end{array}$ & PIPE \\
\hline $\begin{array}{l}\text { FLAG80 } \\
\text { insertion }\end{array}$ & $\begin{array}{l}\text { Forward } \\
\text { Reverse }\end{array}$ & $\begin{array}{l}\text { gactacaaagacgatgacgacaagGCCAAATCCCCCCCTGAATC } \\
\text { cttgtcgtcatcgtcttgtagtcCCAGAAGAAGCCAATGAAAGGC }\end{array}$ & PIPE \\
\hline $\begin{array}{l}\text { FLAG90 } \\
\text { insertion }\end{array}$ & $\begin{array}{l}\text { Forward } \\
\text { Reverse }\end{array}$ & $\begin{array}{l}\text { gactacaaagacgatgacgacaagGAGCAGCTCGAGGCCAGGAG } \\
\text { cttgtcgtcatcgtctttgtagtcCTTATTTTCTGATTCAGGGGGGG } \\
\text { ATTTG }\end{array}$ & PIPE \\
\hline $\begin{array}{l}\text { FLAG100 } \\
\text { insertion }\end{array}$ & $\begin{array}{l}\text { Forward } \\
\text { Reverse }\end{array}$ & $\begin{array}{l}\text { gactacaaagacgatgacgacaagGGAACCAATATTTCAGAAAC } \\
\text { AAGCTTAATAGG } \\
\text { cttgtcgtcatcgtcttgtagtcTTTTCTGCGCCTCCTGGCC }\end{array}$ & PIPE \\
\hline$\Delta 50-60$ & $\begin{array}{l}\text { Forward } \\
\text { Reverse }\end{array}$ & $\begin{array}{l}\text { TACCGCTGTCGCCACCGATCCCAGTTCGCCCTCTTCT } \\
\text { CG } \\
\text { TCGGTGGCGACAGCGGTAGGAGAGCAC }\end{array}$ & $\begin{array}{l}\text { PIPE (primers } \\
\text { designed in [7]) }\end{array}$ \\
\hline$\Delta \mathrm{HA}$ & $\begin{array}{l}\text { Forward } \\
\text { Reverse }\end{array}$ & $\begin{array}{l}\text { cetgactatgcgggCTATCCATATGACGTTCCAGATTAC } \\
\text { aacgtcatatggataGCCCGCATAGTCAGGAACAT }\end{array}$ & PIPE \\
\hline$\Delta(\mathrm{HA})_{2}$ & $\begin{array}{l}\text { Forward } \\
\text { Reverse }\end{array}$ & $\begin{array}{l}\text { ggaattgecettatgTATCCATATGACGTTCCAGATTAC } \\
\text { aacgtcatatggataCATAAGGGCAATTCCACCACA }\end{array}$ & PIPE \\
\hline
\end{tabular}




\section{Supplementary references}

930 1. Chua, N. K., Hart-Smith, G., and Brown, A. J. (2019) Non-canonical ubiquitination of the

2. Gill, S., Stevenson, J., Kristiana, I., and Brown, A. J. (2011) Cholesterol-dependent degradation of

3. Hornbeck, P. V., Zhang, B., Murray, B., Kornhauser, J. M., Latham, V., and Skrzypek, E. (2015)

4. Bryksin, A. V, and Matsumura, I. (2010) Overlap extension PCR cloning: a simple and reliable way to create recombinant plasmids. Biotechniques. 48, 463-465

6. Li, M. Z., and Elledge, S. J. (2007) Harnessing homologous recombination in vitro to generate

7. Chua, N. K., Howe, V., Jatana, N., Thukral, L., and Brown, A. J. (2017) A conserved degron containing an amphipathic helix regulates the cholesterol-mediated turnover of human squalene monooxygenase, a rate-limiting enzyme in cholesterol synthesis. J. Biol. Chem. 292, 19959-19973

8. Goldstein, J. L., Basu, S. K., and Brown, M. S. (1983) Receptor-mediated endocytosis of low-

9. Stevenson, J., Krycer, J. R., Phan, L., and Brown, A. J. (2013) A practical comparison of ligation-

10. Schmittgen, T. D., and Livak, K. J. (2008) Analyzing real-time PCR data by the comparative CT

12. The UniProt Consortium (2017) UniProt: the universal protein knowledgebase. Nucleic Acids Res.

13. Wootton, J. C., and Federhen, S. (1996) Analysis of compositionally biased regions in sequence

11. Zerenturk, E. J., Sharpe, L. J., and Brown, A. J. (2014) DHCR24 associates strongly with the endoplasmic reticulum beyond predicted membrane domains: implications for the activities of this multi-functional enzyme. Biosci. Rep. 34, e00098

960 14. Promponas, V. J., Enright, A. J., Tsoka, S., Kreil, D. P., Leroy, C., Hamodrakas, S., Sander, C.,

15. Harrison, P. M. (2017) fLPS: fast discovery of compositional biases for the protein universe. $B M C$

965 16. Hanson, J., Yang, Y., Paliwal, K., and Zhou, Y. (2017) Improving protein disorder prediction by 

692

17. Mizianty, M., Peng, Z., and Kurgan, L. (2013) MFDp2: accurate predictor of disorder in proteins

18. Wang, S., Ma, J., and Xu, J. (2016) AUCpreD: Proteome-level protein disorder prediction by by fusion of disorder probabilities, content and profiles. Intrinsically Disord. Proteins. 1, e24428

19. Mészáros, B., Erdös, G., and Dosztányi, Z. (2018) IUPred2A: context-dependent prediction of protein disorder as a function of redox state and protein binding. Nucleic Acids Res. 46, W329W337

20. Jones, D. T., and Cozzetto, D. (2015) DISOPRED3: precise disordered region predictions with

977 21. Ishida, T., and Kinoshita, K. (2007) PrDOS: prediction of disordered protein regions from amino acid sequence. Nucleic Acids Res. 35, W460-W464

979 22. Peng, K., Radivojac, P., Vucetic, S., Dunker, A. K., and Obradovic, Z. (2006) Length-dependent 